\title{
Protein Corona Fingerprinting Predicts the Cellular Interaction of Gold and Silver Nanoparticles
}

\author{
Carl D. Walkey, Jonathan B. Olsen, Fayi Song, Rong Liu, \\ Hongbo Guo, D. Wesley H. Olsen, Yoram Cohen, \\ Andrew Emili, and Warren C. W. Chan
}

Version Post-Print/Accepted Manuscript

Citation C. D. Walkey, J. B. Olsen, F. Y. Song, R. Liu, H. B. Guo, D. W. H.

(published version) Olsen, Y. Cohen, A. Emili, W. C. W. Chan, "Protein Corona Fingerprinting Predicts the Cellular Interaction of Gold and Silver Nanoparticles," ACS Nano, 2014 (Feb), 8, 2439-2455. JIF = 12.0.

Publisher's Statement This document is the Accepted Manuscript version of a Published Work that appeared in final form in ACS Nano, copyright (CAmerican Chemical Society after peer review and technical editing by the publisher. To access the final edited and published work see http://dx.doi.org/10.1021/nn406018q. accepted manuscript) because you cannot access the published version, then cite the TSpace version in addition to the published version using the permanent URI (handle) found on the record page. 


\section{Article}

\section{Protein Corona Fingerprinting Predicts the Cell Association of Gold Nanoparticles}

Carl D. Walkey, Jonathan B Olsen, Fayi Song, Rong Liu, Hongbo Guo, Wesley Olsen, Yoram Cohen, Andrew Emili, and Warren C.W. Chan

ACS Nano, Just Accepted Manuscript • DOI: 10.1021/nn406018q • Publication Date (Web): 11 Feb 2014

Downloaded from http://pubs.acs.org on February 14, 2014

\section{Just Accepted}

"Just Accepted" manuscripts have been peer-reviewed and accepted for publication. They are posted online prior to technical editing, formatting for publication and author proofing. The American Chemical Society provides "Just Accepted" as a free service to the research community to expedite the dissemination of scientific material as soon as possible after acceptance. "Just Accepted" manuscripts appear in full in PDF format accompanied by an HTML abstract. "Just Accepted" manuscripts have been fully peer reviewed, but should not be considered the official version of record. They are accessible to all readers and citable by the Digital Object Identifier (DOI@). "Just Accepted" is an optional service offered to authors. Therefore, the "Just Accepted" Web site may not include all articles that will be published in the journal. After a manuscript is technically edited and formatted, it will be removed from the "Just Accepted" Web site and published as an ASAP article. Note that technical editing may introduce minor changes to the manuscript text and/or graphics which could affect content, and all legal disclaimers and ethical guidelines that apply to the journal pertain. ACS cannot be held responsible for errors or consequences arising from the use of information contained in these "Just Accepted" manuscripts. 


\title{
Protein Corona Fingerprinting Predicts the Cell Association of Gold
}

\section{Nanoparticles}

\author{
Carl D. Walkeya,c, Jonathan B. Olsen b,c, Fayi Songa,c, Rong Liug,h, Hongbo Guo b,c, \\ Wesley H. Olsenª,b,c, Yoram Coheng,h, Andrew Emilib,c, and Warren C. W. Chan ${ }^{\mathrm{a}, \mathrm{c}, \mathrm{d}, \mathrm{e}, \mathrm{f} \text {, }}$
}

\begin{abstract}
anstitute of Biomaterials and Biomedical Engineering, bBanting and Best Department of Medical
Research, 'Donnelly Centre for Cellular and Biomolecular Research, ${ }^{\mathrm{d} D e p a r t m e n t ~ o f ~ C h e m i c a l ~}$

Engineering, eDepartment of Chemistry, fDepartment of Materials Science and Engineering,

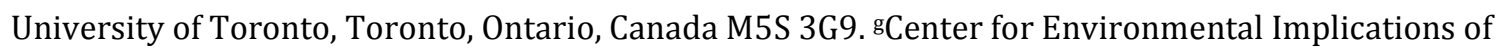

Nanotechnology, California Nanosystems Institute, ${ }^{\mathrm{h} C h e m i c a l ~ a n d ~ B i o m o l e c u l a r ~ E n g i n e e r i n g ~}$

Department, University of California, Los Angeles, CA 90095, USA.
\end{abstract}

*Address correspondence to warren.chan@utoronto.ca

\section{TOC Graphic}

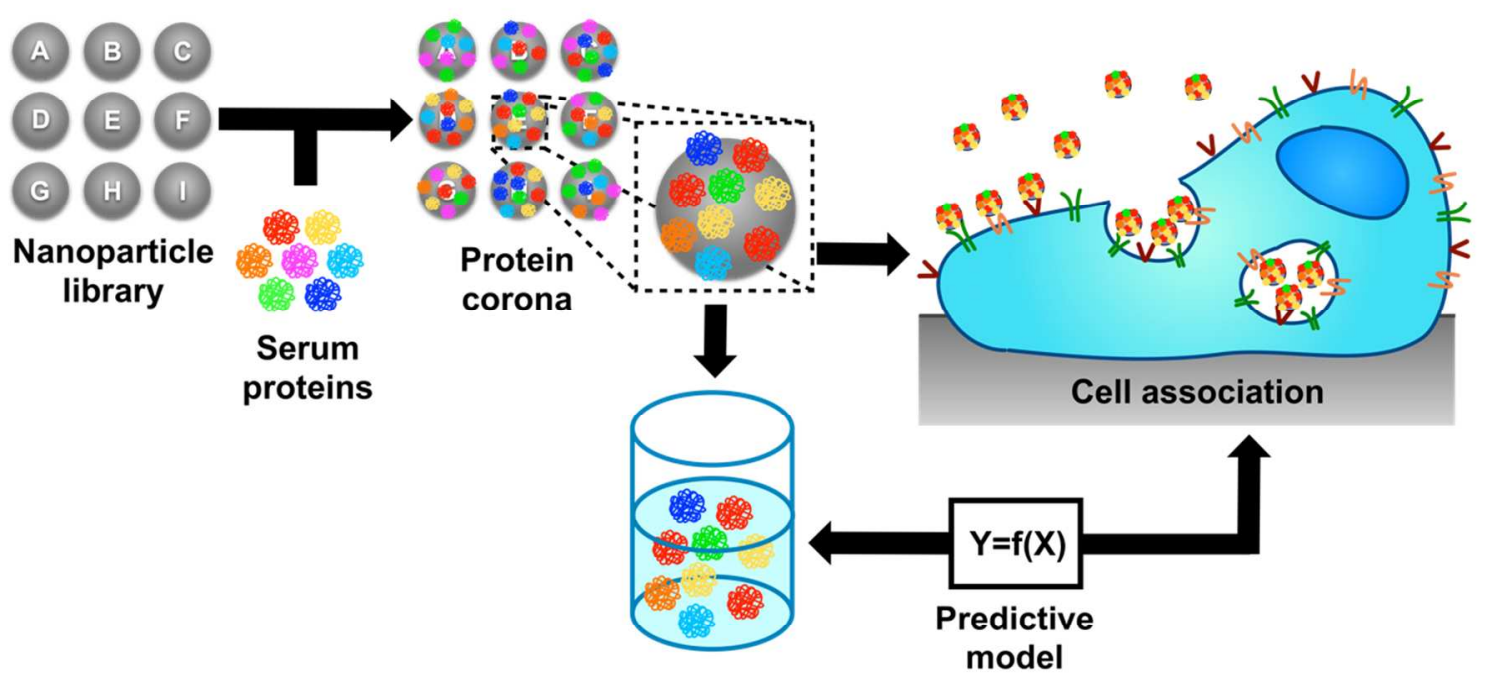

\begin{abstract}
Using quantitative models to predict the biological interactions of nanoparticles will accelerate the translation of nanotechnology. Here, we characterized the serum protein corona 'fingerprint' formed around a library of 105 surface-modified gold nanoparticles. Using a bioinformatics-inspired approach, we developed a multivariate model that uses the protein corona fingerprint to predict cell
\end{abstract}


association 50\% more accurately than a model that uses parameters describing nanoparticle size, aggregation state, and surface charge. Our model implicates a set of hyaluronan-binding proteins as mediators of nanoparticle-cell interactions. This study establishes a framework for developing a comprehensive database of protein corona fingerprints and biological responses for multiple nanoparticle types. Such a database can be used to develop quantitative relationships that predict the biological responses to nanoparticles and will aid in uncovering the fundamental mechanisms of nano-bio interactions.

Keywords: protein corona; cell uptake; structure-activity model; liquid chromatography tandem mass spectromery; quantitative proteomics; nanomedicine; nanobiotechnology

Advances in materials science, engineering, and nanotechnology have led to the development of nanoparticles with diverse sizes, shapes, and compositions. ${ }^{1}$ The size- and shape-dependent electronic, optical, and magnetic properties of nanoparticles have been exploited to develop faster electronics, brighter displays, and more sensitive diagnostic agents for medical imaging. ${ }^{2-7}$ The biological interactions of a nanoparticle are a function of its physicochemical properties, such as size, shape, and surface chemistry. However, establishing correlations between nanoparticle properties and biological interactions is challenging because of the complexity of biological systems at the molecular, cellular, and tissue level and because there are a nearly infinite number of nanomaterial design permutations..$^{8-10}$ To date, the influence of nanoparticle properties on in vitro cell uptake and toxicity, and in vivo pharmacokinetics and biodistribution has only been established for a limited number of nanoparticle types. ${ }^{11,12}$

Researchers are developing qualitative and quantitative structure-activity relationships (SARs) that relate nanoparticle properties to observed biological responses. ${ }^{13-15}$ SARs can predict the biological behavior of nanoparticles without explicit experimentation, and uncover the fundamental mechanisms of nano-bio interactions. Studies have shown that the biological response to a nanoparticle 
formulation is, in general, a complex function of multiple physicochemical properties. ${ }^{16,17}$ While some SARs show relatively good performance when predicting simple biological interactions and responses, few are capable of accurately predicting complex biological responses, such as cell association, over large and chemically-diverse nanoparticle libraries. ${ }^{18}$

To date, published SARs have used nanoparticles properties that are characterized post-synthesis. ${ }^{19}$ However, when a nanoparticle enters a biological environment, it comes into contact with a biofluid that contains a diverse mixture of proteins and other biomolecules. Unless the nanoparticle is intentionally designed to avoid it, a subset of these proteins will adsorb onto its surface, forming a protein 'corona'.20, 21 The protein corona establishes a 'biological identity' for the nanoparticle that is distinct from its 'synthetic identity'. ${ }^{22}$ Protein-nanoparticle interactions also change the size, shape, and aggregation state of the nanoparticle, which alters the presentation of adsorbed proteins to their biomolecular targets. ${ }^{23}$, 24 The biological identity is the form of the nanoparticle that is 'seen' by the components of the biological system, and influences the downstream biological behaviour. ${ }^{25}$ Indeed, studies have shown that the presence of serum proteins within in vitro cell culture systems alters nanoparticle-cell interactions and the cell response. ${ }^{26,27}$ The protein corona thus encodes information about the interface formed between the nanoparticle and the cell surface within a physiological environment. Here, we used the composition of the protein corona 'fingerprint' to predict the cell association of a 105-member library of chemically-diverse gold nanoparticles (Fig. 1). Cell association was chosen as a model biological interaction because of its relevance to inflammatory responses, biodistribution, and toxicity in vivo. ${ }^{28-30}$

\section{Results and Discussion}

We used a combinatorial approach to prepare a library of 105 distinct surfacemodified gold nanoparticles with 15, 30, or 60nm cores (Fig. 2A). The 67 organic surface ligands used to create the library include small molecules, polymers, 
peptides, surfactants, and lipids, and were chosen to mimic the surface chemistries of many of the most widely used nanoparticle formulations. ${ }^{31}$ The surface ligands were classified as 'neutral', 'anionic', or 'cationic' based on their chemical structure and net charge at physiological pH (Table S1). A detailed description of each formulation is provided in Table S2. Transmission electron microscopy (TEM) confirmed that the nanoparticle cores were monodisperse and had uniform morphology (Fig. S1). After surface modification, we used dynamic light scattering (DLS) to measure the hydrodynamic diameter (HD) of each formulation, and absorbance spectrophotometry (AS) to measure the localized surface plasmon resonance index (LSPRi) and LSPR peak wavelength (LSPR peak) (Fig. S2 and S3). The electrophoretic mobility and zeta potential (ZP) were characterized using light scattering and agarose gel electrophoresis (Fig. S4 and S5). Statistically significant changes in HD, LSPR $\mathrm{peak}_{\text {, }}$ or ZP were observed during the surface modification of the gold nanoparticle cores by all ligands except phenylalanine (Phe) (Table S3). Since Phe associates with the gold nanoparticle surface by forming relatively weak hydrophobic and ionic interactions, it probably dissociates during post-synthetic purification. We used the Ellman depletion assay to further quantify the surface density of a subset of thiolated small molecules (Fig. S6). Assuming a footprint of $0.22 \mathrm{~nm}^{2}$ (the effective footprint of an adsorbed thiol on a gold substrate), the surface density of the ligands ranges from sub-monolayer to multilayer depending on gold nanoparticle core size and the chemical structure of the ligand. The small relative standard deviation of the HD, ZP, and LSPRi across independent replicate syntheses confirms the reproducibility of the synthetic procedures (see Supplementary Database).

After synthesis, each formulation was incubated with undiluted human serum for $1 \mathrm{~h}$ at $37^{\circ} \mathrm{C}$ and purified using centrifugation to remove unbound proteins. Blood serum was chosen to simulate the biomolecular environment that a nanoparticle encounters following intravenous exposure and during in vitro cell culture experiments. It should be noted that serum is not a perfect model for the in vivo environment, since key blood coagulation factors are absent. The composition of the 
protein corona around each formulation was characterized qualitatively using poly(acrylamide) gel electrophoresis (PAGE) (Fig. S7) and quantitatively using highresolution label-free shotgun tandem mass spectrometry (LC-MS/MS). ${ }^{32-34}$ The accuracy and reproducibility of the LC-MS/MS characterization was established using protein mixtures of known composition and independent experimental replicates (Fig. S9 and S11). The abundance of several key adsorbed serum proteins was further confirmed by Western blotting (Fig. S12). On average, each formulation adsorbed $71 \pm 22$ distinct serum proteins. The total number of identified proteins as well as the total adsorbed protein density depends on nanoparticle core size and surface ligand chemistry (Fig. 2B and S10). Typically, for a fixed core size, nanoparticles modified with anionic or cationic ligands adsorbed more protein than those modified with neutral ligands, reflecting a greater propensity for proteins to associate with charged nanoparticles via electrostatic interactions. ${ }^{32}$ For a given surface ligand, formulations with smaller cores typically adsorbed a higher density of serum protein than those with larger cores, since the lower surface curvature on larger nanoparticles creates greater steric hindrance between adjacent adsorbed proteins. 35

Serum incubation led to a statistically significant change in the HD, LSPRi, and ZP of most formulations (Fig. S2-S4). Biomolecule-nanoparticle interactions in serum that lead to biomolecule adsorption or loss of colloidal stability increase the HD and LSPRi, whereas biomolecular interactions that lead to surface modifier loss or dispersion decrease the HD and LSPRi relative to the values measured postsynthesis. ${ }^{23,24,36-43}$ Serum exposure 'normalized' the ZP to an average value of $7.8 \pm 2.6 \mathrm{mV}$. As a result, the change in $\mathrm{ZP}$ after serum exposure is a linear function of the ZP after synthesis (Fig. S8). Most serum proteins have an isoelectric point between pH 6 and 7, and thus carry a net negative charge at pH 7.4. Upon adsorption, the anionic serum proteins impart a net negative charge to the nanoparticles. ${ }^{34,44-48}$ 
Over the entire library, 785 distinct serum proteins were identified by LCMS/MS, of which 129 were suitable for relative quantification (Table S5). The relative abundance of each of these proteins on a nanoparticle formulation defines the serum protein 'fingerprint' for that formulation (Fig. 3). Our data confirms that the relative abundance of proteins in the corona does not, in general, reflect their relative abundance in serum because low abundance proteins are selectively enriched on the nanoparticle surface. 32 , 33, 49-51 To provide functional information, identified proteins were screened for their involvement in coagulation, complement activation, lipid transport, inflammation, and cell association using gene ontology (GO) terms (Table S5).

After characterizing the protein corona, we used inductively coupled plasmaatomic emission spectroscopy (ICP-AES) to measure nanoparticle association with A549 human lung epithelial carcinoma cells in a monolayer culture. These cells are widely used as a model to study fundamental nanoparticle-cell interactions. Cell association, which includes internalization of the nanoparticles and adhesion to the cell membrane, spanned more than two orders of magnitude across the gold nanoparticle library (Fig. 2C). On average, cationic gold nanoparticle formulations associated with cells to a greater extent than anionic or neutral formulations, consistent with previous studies. ${ }^{52,53}$ However, there was considerable variability within each group, suggesting that features of the nanoparticle interface other than the sign of the net charge also influence cell association.

To determine the extent to which individual proteins within the serum protein fingerprint predict cell association, we developed a series of log-linear models that relate the relative abundance of each adsorbed serum protein to net cell association. Each model has the form

$$
\log _{2}\left(\hat{y}_{i}\right)=a_{j} x_{i, j},(\text { eq. } 1)
$$


Where $\hat{y}_{i}$ is the model estimate of the cell association of formulation ' $i$ ', $x_{i, j}$ is the relative abundance of serum protein ' $j$ ' on formulation ' $i$ ', and $a_{j}$ is the model parameter that is fit during training. Neutral formulations were excluded during model training because they resisted serum protein adsorption. The fitting accuracy of each model was quantified using the coefficient of determination $\left(R^{2}\right)$, while the prediction accuracy was quantified using the coefficient of determination under 'leave-one-out' (LOO) cross-validation $\left(\mathrm{Q}^{2} \mathrm{LOO}\right)$. Values of $\mathrm{R}^{2}$ or $\mathrm{Q}^{2} \mathrm{Loo}$ closer to unity indicate a more accurate model, and imply that a particular protein encodes more information about the nanoparticle that is relevant to cell association. The $\mathrm{Q}^{2} \mathrm{Loo}$ was 0.44 for the most predictive protein, $\alpha-1$ microglobulin (AMBP). Values of $a_{i}$ for each protein, along with parameters characterizing model performance are reported in Table S6. Proteins that are more highly correlated with cell association tend to generate models that are more accurate.

To determine whether the predictive accuracy of the model could be improved by using multiple adsorbed proteins simultaneously, a new model was developed that describes net cell association as the sum of the adsorbed densities of each protein within the serum protein fingerprint. This model has the form:

$$
\log _{2}\left(\hat{y}_{i}\right)=\sum_{j=1}^{m} b_{j} x_{i, j},(\text { eq. } 2)
$$

Where ' $m$ ' is the total number of proteins in the serum protein fingerprint used in the model, and $b_{j}$ is a model parameter that relates the relative abundance of protein ' $j$ ' to the cell association of formulation ' $i$ '. Because there are 129 proteins in the serum protein fingerprint, but only 84 formulations available in the data set, finding a unique solution using multiple least squares regression would require at least 45 additional formulations. We made two observations that decreased the number of parameters being fit in the model. First, the adsorption of some pairs of serum proteins is highly correlated (Fig. 3). Highly correlated proteins can be combined using a single effective parameter. Second, some serum proteins within 
the fingerprint are only weakly correlated with cell association (Fig. 3). These proteins can be de-emphasized or eliminated from the model. We used a bioinformatics modeling technique, known as partial least squares regression (PLSR), to incorporate both of these operations during model training. ${ }^{54}$ PLSR was implemented with an iterative parameter reduction algorithm that selected the 64 most predictive proteins for model training (Fig. S14). Over the nanoparticle library used here, the resulting model predicted cell association with a $\mathrm{Q}^{2} \mathrm{LOO}$ of 0.81 (Fig. 4A,B). For a more stringent test, we calculated the coefficient of determination under 'leave many out' cross-validation $\left(Q^{2}{ }_{\text {LMO25\% }}\right.$ ), which was $0.61 \pm 0.18$ (Table 1 ). The $b_{\mathrm{i}}$ value for each of the proteins used in the model is reported in Table S7. Analysis of the applicability domain shows that none of the formulations are outliers (Fig. S15 and table S8). The multivariate model that uses the serum protein fingerprint predicts cells association with 84\% higher accuracy than the best performing model that uses only single serum proteins (eq.1), showing that distinct serum proteins within the fingerprint encode non-redundant information about the nanoparticles that can be used to enhance the accuracy of the prediction. This result suggests that multiple serum proteins are needed to adequately describe the complex nature of the nanoparticle interface that a cell encounters within a biological environment. ${ }^{36}$ Although the accuracy of the predictions made by the model are considered acceptable by conventional standards, ${ }^{55}$ the accuracy may be further improved by taking into account distinct characteristics of the biomolecular corona that are important for mediating cell association including the conformation, orientation, and structure of the adsorbed proteins, as well as the lipid, small molecule, and polysaccharide fingerprints. ${ }^{56,57}$

Surface-adsorbed serum proteins may either promote cell association or inhibit it. $^{26,58}$ The sign of the $b_{i}$ coefficient for each protein reflects the correlation between the adsorbed serum protein and cell association. Coefficients with positive signs indicate that, all other things being equal, greater adsorption of that protein on a formulation implies greater cell association, suggesting that the protein mediates cell association. In contrast, coefficients with negative signs indicates that, all other 
things being equal, greater adsorption of that protein implies lower cell association, suggesting that the protein inhibits cell association. Thus, the multivariate model provides implicit information about the function of each protein within the serum protein fingerprint. Of the 64 serum proteins used to create the model, 39 are classified as promoters of cell association and 25 as inhibitors (Table S7). Each of these proteins was ranked according to its importance to the model. Five of the most influential promoters, inter-alpha trypsin inhibitor heavy chains $\mathrm{H} 1, \mathrm{H} 2$, and H3 (ITIH1, ITIH2, and ITIH3), $\alpha$-1 microglobulin (AMBP), and hyaluronan-binding protein 2 (HABP2) are involved in hyaluronan binding. Since hyaluronan is a major component of cell-surface glycoproteins and the extracellular matrix, surfaceadsorbed hyaloronan-binding proteins may act as 'bridges' that mediate the interaction of nanoparticles with the cell surface. ${ }^{59,60}$ The most influential inhibitor is complement C3. Although C3 has a putative role as an opsonin when it is adsorbed to the surface of foreign or pathogenic materials, because of its high molecular weight (approximately $190 \mathrm{kDa}$ ), it may also act as an inhibitor in the absence of specific cell surface receptor interactions by blocking the interaction of cell surface biomolecules with the underlying nanoparticle surface or other adsorbed proteins. ${ }^{61}$

Because the model (Eq.2) classifies proteins as promoters or inhibitors of cell association through correlative relationships, causality is not implied. To elucidate the role of serum hyaluronan-binding proteins in nanoparticle-cell association, we quantified the cell association of cationic AUT- and MUTA-modified 15nm gold nanoparticles in the presence of free hyaluronic acid (HA). HA inhibited cell association in a concentration-dependent manner, suggesting that the interaction of adsorbed hyaluronan-binding proteins with cell-surface hyaluronan mediates nanoparticle-cell association (Fig. S16). However, since even high concentrations of HA only partially inhibit cell association, it is likely that other hyaluronanindependent mechanisms also contribute. 
To determine the accuracy of models generated using subsets of the most predictive adsorbed serum proteins, we iteratively extracted the least influential protein and fit a new model (using Eq.2) that uses the remaining proteins. Models that use the top $48,32,16$, or 6 serum proteins are $99 \%, 95 \%, 83 \%$, or $74 \%$ as accurate as the full model (Fig. 4C). The identities of the selected protein subsets are important, since randomly selected proteins generated models with significantly lower prediction accuracy (Fig. 4C). The abundances of small subsets of proteins can be characterized using targeted mass spectrometry, Western blot, and ELISA. These techniques are often simpler and less resource-intensive than full LC-MS/MS characterization.

It has been suggested that nanoparticle formulations with a higher protein binding capacity associate with cells more efficiently than those with a lower protein binding capacity. ${ }^{62,63}$ To test this assertion, we developed a linear model that describes cell association as a function of the total adsorbed serum protein density. The model shows nearly no prediction accuracy $\left(\mathrm{Q}^{2} \mathrm{LOO}=0.0088\right)$ relative to the model that uses the full protein fingerprint (Fig. S17E). This result suggests that total adsorbed protein density does not 'encode' the molecular details of the nanoparticle surface that are important for describing how it will interact with cells. These details are, however, captured by the identities and abundances of the proteins within the serum protein fingerprint. While total serum protein adsorption may predict cell association over a relatively limited number of formulations with similar surface functional groups and charges, it does not accurately predict cell association over nanoparticle libraries with diverse interface chemistries.

Since the size, aggregation state, and surface charge density of a nanoparticle influence its cell association, we asked how accurately models using parameters derived from DLS, TEM, AS, and ZP characterization predict cell association. 24, 8, 5, and 1 parameter(s) were extracted from DLS, ZP, AS, and TEM measurements (respectively) (Table S9). Using PLSR, we created a series of multivariate linear models that predict cell association with a $\mathrm{Q}^{2} \mathrm{LOO}$ of 0.23 (DLS), 0.065 (TEM), 0.24 
(AS), and 0.43 (ZP) (Fig. 4a, S17, and S18, and Table 1). Each model had the same form as in Eq.2. Models using parameters describing the ZP predict cell association more accurately than parameters derived from DLS, AS, or TEM, indicating that surface charge encodes more information about the nanoparticles that is relevant to predicting cell association than nanoparticle size and aggregation state. A combined model that uses all parameter sets together has slightly higher predictive accuracy than the model that uses only ZP, indicating that most of the structural information about the nanoparticles that is relevant to predicting cell association is redundant between these parameter sets. The model that uses the full serum protein fingerprint predicts cell association with 50\% higher accuracy than the combined model. Since cells recognize nanoparticles through molecular interactions at the interface, the serum protein fingerprint more accurately reflects characteristics of the nanoparticles that determine cell association than DLS, ZP, TEM, and AS measurements. Interestingly, a combined model that uses DLS, TEM, AS, and ZP along with the serum protein fingerprint predicts cell association with $\mathrm{Q}^{2} \mathrm{LOO}$ of 0.86 , which is only marginally more accurate than the model that uses the serum protein fingerprint alone, suggesting that the serum protein fingerprint encodes information about the size, surface charge, and aggregation state of the nanoparticles.

To assess how accurately the gold nanoparticle model predicts the cell association of a different nanoparticle type, we prepared a set of 16 silver nanoparticle formulations by grafting $39 \mathrm{~nm}$ silver nanoparticle cores with a subset of the surface ligands used to prepare the gold nanoparticle library. These formulations were characterized in an identical manner to the gold nanoparticles. The model developed using the serum protein fingerprint around gold nanoparticles predicted the cell association of the silver nanoparticle library with an external prediction accuracy $\left(\mathrm{Q}^{2}\right.$ external) of 0.045 , indicating that a model derived using gold nanoparticles can not be applied to accurately predict the cell association of silver nanoparticles (Fig. 5A and S19). Using a combined model that includes both gold nanoparticles and silver nanoparticles marginally improved the prediction accuracy 
( $\mathrm{Q}^{2}$ LOo of 0.091) (Fig. S19). However, a distinct model created using only the silver nanoparticles predicted cell association with a $\mathrm{Q}^{2} \mathrm{L00}$ of 0.79 (Fig. 5B and S19). These results show that the way in which the adsorbed serum protein fingerprint is related to cell association depends on nanoparticle core type, suggesting that there are particle-dependent differences in the orientation, conformation, and structure of the adsorbed protein layer and the mechanisms of nanoparticle-cell interactions that are not reflected in the identities and quantities of the adsorbed serum proteins. We conclude that distinct models may be required to accurately predict the cell association of different nanoparticle classes from the serum protein fingerprint, even though a consistent LC-MS/MS characterization of the protein corona can be used.

In addition to relating the characteristics of the protein corona to downstream biological interactions, there is considerable interest in understanding the influence of nanoparticle physical and chemical properties on the formation of the protein corona. Using the dataset collected in this study, we characterized the extent to which gold nanoparticle core size influences the composition of the serum protein corona. On average, $74.7 \%$ of the serum protein corona formed around $15 \mathrm{~nm}$ gold nanoparticles is common to $30 \mathrm{~nm}$ gold nanoparticles modified with the same surface ligand, while $86.7 \%$ of the serum protein corona formed around $30 \mathrm{~nm}$ gold nanoparticles is common to $60 \mathrm{~nm}$ gold nanoparticles (Fig. S20A). Since, on average, $95.0 \%$ of the serum protein corona is common between independent experimental replicates, nanoparticle size has a significant influence on the composition of the protein corona, consistent with previous studies. $33,47,49$ In comparison, $47.2 \%$ of the serum protein corona formed around cationic amine-functionalized gold nanoparticles is common to anionic carboxy-functionalized gold nanoparticles, and $65.9 \%$ of the serum protein corona formed around trimethylammoniumfunctionalized gold nanoparticles is common to amine-functionalized gold nanoparticles. This shows that surface functional group chemistry has a greater influence than nanoparticle size on protein corona composition, at least in the range of 15 to $60 \mathrm{~nm}$. Nanoparticle size may influence the composition of the protein 
corona by changing the deflection angle between adjacent adsorbed proteins or by altering the curvature of the interface 'seen' by incoming proteins. ${ }^{35,64,65}$ Although it is beyond the scope of this study, correlating nanoparticle size-dependent changes in the relative abundance of individual adsorbed serum proteins to protein molecular weight, structure, and charge may provide further insights.

To study the influence of nanoparticle core material on protein corona composition, we computed the global similarity in the serum protein corona formed around gold and silver nanoparticles. On average, only $36.9 \%$ of the serum protein corona formed around silver nanoparticles is common to gold nanoparticles modified with the same surface ligand (Fig. S20B), showing that the core material exerts a greater influence on protein corona composition than core size or surface functional group. This finding is counterintuitive, since the core is 'shrouded' by the surface ligand layer. However, even if the ligand-protected core does not make direct contact with proteins in the surrounding biological environment, it determines the density, arrangement, and orientation of the associated ligands. Detailed study of the nanoparticle surface using X-ray photoelectron spectroscopy, time-of-flight secondary ion mass spectrometry, or atomic force microscopy may provide additional insights.

\section{Conclusions}

In this study, we developed a quantitative model that uses the serum protein corona fingerprint to predict the cell association of a compositionally-diverse gold nanoparticle library. This model is 50\% more accurate than a model that uses nanoparticle size, aggregate state, and surface charge, suggesting that the protein corona encodes more biologically-relevant information about a nanoparticle than its physical properties. This study includes the most comprehensive quantitative characterization of the blood protein corona published to date and establishes a framework for a database of protein coronae and corresponding biological responses for nanoparticle formulations with well-defined properties. Measurements of core size, hydrodynamic diameter, zeta potential, LSPR index, total 
adsorbed protein density, cell association, and spectral counts for each identified serum protein are made freely available in the Supplementary Database.

The protein corona fingerprinting strategy can be extended to predict the association of nanoparticles with other physiologically-relevant cell types, such as endothelial cells, macrophages, and hepatocytes. Since nanoparticle-cell interactions determine downstream cellular responses, the protein corona fingerprint may also predict the activation of intra-cellular signaling cascades, cytokine secretion, gene expression, toxicity, and, by extension, in vivo pharmacokinetics, biodistribution, and organ response. Provided the appropriate models have been established, it is theoretically possible to predict multiple biological interactions and responses from a single characterization of the protein corona fingerprint. Moreover, since a protein corona forms around silica, metal oxide, lipid, and polymer nanoparticles, protein corona fingerprinting is applicable across nanoparticle classes, although distinct models may be required. The results presented in this study suggest that protein corona fingerprinting may be developed into a general strategy to predict the interaction of nanoparticles with biological systems.

To realize more accurate and precise findings, there is a need to develop and apply large libraries of nanoparticles. In order to maximize the use of large datasets, a database system must be established that includes nanoparticle properties and corresponding biological interactions. Such a database will be valuable to the broader research community, as it will allow biological interactions to be modeled without the need for extensive experiments. Using the recently proposed alphanumeric nomenclature system, it is now possible to index nanomaterials according to their physical and chemical properties. ${ }^{66}$ This will allow the database to be searched for biological data associated with nanoparticles possessing specific properties. Strategies to model nano-bio interactions will converge with developments in the fields of bioinformatics and systems biology. Ultimately, developing a database of nanoparticle properties and their corresponding biological 
interactions will lead to the establishment of predictive models that will guide the design of nanoparticles for diverse applications (Fig. 6).

\section{Materials and Methods \\ Preparation of gold nanoparticle cores}

$15 \mathrm{~nm}$ gold nanoparticles (GNPs) were prepared by citrate reduction of an aqueous ionic gold precursor as described before. ${ }^{67}$ Briefly, $100 \mathrm{~mL} 0.25 \mathrm{mM}$ aqueous gold(III) chloride (Sigma, cat\#:520918) was brought to boil in a 250mL Erlenmeyer flask containing a 1.5" Teflon-coated magnetic stir-bar. Under vigorous stirring, $1 \mathrm{~mL}$ $3.3 \%(\mathrm{w} / \mathrm{v})$ aqueous sodium citrate dibasic trihydrate (Sigma, cat\#:S4641) was rapidly added. Boiling and stirring were continued for 10 minutes, producing a redcolored solution. The solution was cooled in an ice bath and diluted to $100 \mathrm{~mL}$ with water.

$30 \mathrm{~nm}$ and $60 \mathrm{~nm}$ gold nanoparticles were prepared using an adaptation of the seed-mediated growth procedure described by Perrault and Chan. ${ }^{68}$ Briefly, $888 \mathrm{uL}(30 \mathrm{~nm})$, or $985 \mathrm{uL}(60 \mathrm{~nm}) 0.25 \mathrm{mM}$ aqueous gold (III) chloride was added to a $250 \mathrm{~mL}$ Erlenmeyer flask containing $86.1 \mathrm{~mL}(30 \mathrm{~nm})$, or $95.6 \mathrm{~mL}(60 \mathrm{~nm})$ water and cooled to $4^{\circ} \mathrm{C} .888 \mathrm{uL}(30 \mathrm{~nm})$, or $985 \mathrm{uL}(60 \mathrm{~nm})$ of $15 \mathrm{mM}$ aqueous sodium citrate tribasic dihydrate were added. Under stirring, $11.3 \mathrm{~mL}(30 \mathrm{~nm})$, or $1.64 \mathrm{~mL}(60 \mathrm{~nm})$ of $15 \mathrm{~nm}$ gold nanoparticles, prepared as described above, were added. Growth was initiated by adding $888 \mathrm{uL}(30 \mathrm{~nm})$, or $985 \mathrm{uL}(60 \mathrm{~nm})$ of $25 \mathrm{mM}$ aqueous hydroquinone (Sigma, cat\#:H17902). The flask was returned to room temperature and stirring was continued overnight to complete growth.

After synthesis, gold nanoparticles were concentrated to $\sim 25$ times the synthesized concentration and washed to remove reaction byproducts by centrifugation at 7,000g $(15 \mathrm{~nm}), 3,500 \mathrm{~g}(30 \mathrm{~nm})$, or $1,000 \mathrm{~g}(60 \mathrm{~nm})$ for 45 minutes at room temperature. Stock solutions were stored at $4^{\circ} \mathrm{C}$ in the dark until surface modification.

\section{Preparation of silver nanoparticle cores}

$\sim 40 \mathrm{~nm}$ silver nanoparticles were synthesized using a modification of a procedure 
described before. ${ }^{69}$ After synthesis, silver nanoparticles were centrifuged and washed to remove reaction byproducts. Particles were stored at $4^{\circ} \mathrm{C}$ in the dark until surface modification.

\section{Transmission electron microscopy (TEM)}

The average diameter and morphology of each batch of gold and silver nanoparticle cores was characterized by TEM. Carbon-coated copper grids (Ted Pella) were cleaned using a glow discharge lamp. A $5 \mathrm{uL}$ aliquot of the nanoparticle stock solution was drop cast onto the grid. Grids were visualized with an accelerating voltage of $200 \mathrm{kV}$ on a Tecnai 20 (FEI) microscope. An average of 10 images per sample were collected using an AMT 16000 camera (Advanced Microscopy Techniques). Images were imported into Image (NIH) and converted to binary. The area and circularity of the 2D projection of at least 50 distinct nanoparticles per sample was collected. To estimate the effective diameter of each nanoparticle, the total area of the nanoparticle projection was equated to the surface area of a circle and solved for the diameter. Representative TEM images of each sample are shown in Fig. S1. The average diameter of each batch of nanoparticles is reported in the Supplementary Database.

\section{Surface modification of gold and silver nanoparticle cores}

Depending on the surface ligand, one of 10 distinct procedures (see below) was used to surface-modified gold and silver nanoparticle cores. Table S1 lists the procedure for each surface ligand. Each procedure describes the surface modification of nanoparticle cores with a total surface area of $40 \mathrm{~cm}^{2}$. For larger quantities, each procedure was scaled accordingly. Surface-modified nanoparticle cores were stored at $4^{\circ} \mathrm{C}$ in the dark until use.

Surface ligands were classified according to their chemical structure (Supplementary Table S1). 'Neutral' surface ligands possess chemical motifs that do not carry at net charge at physiological $\mathrm{pH}$, resist biomolecule interactions, and stabilize nanoparticle formulations by steric repulsion. Charged ligands possess at least one chemical functional group that carries a net charge at physiological $\mathrm{pH}(\mathrm{pH}$ 
7.4), and stabilize nanoparticles by charge-charge repulsion. Charged ligands were classified as either 'cationic' or 'anionic', depending on whether their overall charge is positive or negative (respectively) at physiological $\mathrm{pH}$.

Procedure 1: A 100uL aliquot of 3mM aqueous sodium citrate dibasic trihydrate (Sigma, cat\#:S4641), or 3mM aqueous L-phenylalanine (Sigma, cat\#:P2126) was transferred to a microcentrifuge tube. A $40 \mathrm{~cm}^{2}$ aliquot of the appropriate gold or silver nanoparticle core stock was centrifuged to concentrate. The supernatant was discarded and the pellet was re-suspended to $900 \mathrm{uL}$ with water and added to the ligand aliquot. The sample was mixed thoroughly and incubated at room temperature overnight. The mixture was centrifuged at 7,000g (15nm GNP), 2,500g (30nm GNP), 1,000g (60nm GNP), or 3,000g (40nm SNP) for 60 minutes at room temperature to pellet the surface-modified nanoparticles. The supernatant was discarded and the pellet was re-suspended in $40 \mathrm{uL}$ of water.

Procedure 2: A 100uL aliquot of 3mM N-acetyl-L-cysteine (Sigma, cat\#:A7250) in ethanol, 1.5mM 5,5'-dithiobis(2-nitrobenzoic acid) (Sigma, cat\#:D8130) in ethanol, $3 \mathrm{mM} \alpha$-lipoic acid (Sigma, cat\#:62320) in ethanol containing 3mM sodium hydroxide, 3mM mercaptoacetic acid (Sigma, cat\#:T3758) in ethanol, 3mM 4mercaptobenzoic acid (Sigma, cat\#:706329) in ethanol, 3mM aqueous sodium 2mercaptoethanesulfonate (Sigma, cat\#:63705), 3mM 6-mercaptohexanoic acid (Sigma, cat\#:674974) in ethanol, 3mM 16-mercaptohexadecanoic acid (Sigma, cat\#:448303) in ethanol, 3mM 3-mercaptopropionic acid (Sigma, cat\#:M5801) in ethanol, 3mM mercaptosuccinic acid (Sigma, cat\#:88460) in ethanol, 3mM 11mercaptoundecanoic acid (Sigma, cat\#:450561) in ethanol, or 3mM N-(2mercaptopropionyl)glycine (Sigma, cat\#:M6635) in ethanol was transferred to a microcentrifuge tube. A $40 \mathrm{~cm}^{2}$ aliquot of the appropriate nanoparticle core stock was centrifuged to concentrate and re-suspended to $900 \mathrm{uL}$ with water, added to the ligand aliquot, and mixed thoroughly. The sample was incubated at $60^{\circ} \mathrm{C}$ for $1 \mathrm{~h}$ to complete ligand exchange, and then cooled to room temperature. The nanoparticle suspension was stabilized by adding $10 \mathrm{uL}$ of $300 \mathrm{mM}$ aqueous 
tetramethylammonium hydroxide (TMAH) (Sigma, cat \#:T7505) and washed once into $1 \mathrm{~mL} 3 \mathrm{mM}$ aqueous TMAH by centrifugation at 7,000g (15nm GNP), 2,500g (30nm GNP), 1,000g (60nm GNP), or 3,000g (40nm SNP) for 60 minutes at room temperature. Nanoparticles were pelleted by centrifugation. The supernatant was removed and the nanoparticle pellet was re-suspended in $40 \mathrm{uL}$ of water.

Procedure 3: A 100uL of 30mM (11-mercaptoundecyl)tetra(ethylene glycol) (Sigma, cat\#:733385) in ethanol, 3mM (11-mercaptoundecyl)-N,N,N-trimethylammonium (Sigma, cat\#:674508) in ethanol, or 3mM aqueous bis(psulfonatophenyl)phenylphosphine (Strem, cat\#:15-0463) was transferred to a microcentrifuge tube. A $40 \mathrm{~cm}^{2}$ aliquot of the appropriate gold or silver nanoparticle core stock was centrifuged to concentrate. The supernatant was removed and the pellet was re-suspended to $900 \mathrm{uL}$ with water and added to the ligand stock. The sample was incubated for 1 hour at $60^{\circ} \mathrm{C}$ and then cooled to room temperature. Surface-modified nanoparticles were washed once in $1 \mathrm{~mL}$ water by centrifugation at 7,000g (15nm GNP), 3,500g (30nm GNP), 1,000g (60nm GNP), or 3,000g (40nm SNP) for 60 minutes at room temperature. The mixture was centrifuged to concentrate the nanoparticles. The supernatant was removed, and the pellet was resuspended in $40 \mathrm{uL}$ of water.

Procedure 4: 0.25mg/mL stock solutions of peptide sequences 'CALNN' (BioBasic), 'CVVIT' (BioBasic), or 'CFGAILS' (BioBasic) were prepared in 3mM aqueous sodium hydroxide. A 100uL aliquot of the appropriate peptide stock was transferred to a new microcentrifuge tube, followed by $10 \mathrm{uL} 300 \mathrm{mM}$ aqueous sodium hydroxide and $290 \mathrm{uL}$ water. A $40 \mathrm{~cm}^{2}$ aliquot of the appropriate gold or silver nanoparticle core stock was centrifuged to concentrate. The supernatant was discarded and the pellet was re-suspended in $600 \mathrm{uL}$ water and added to the peptide aliquot. The sample was mixed thoroughly and incubated at $60^{\circ} \mathrm{C}$ for $1 \mathrm{~h}$ to complete ligand exchange, before being cooled to room temperature. Surface-modified nanoparticles were washed twice in $1 \mathrm{~mL} 3 \mathrm{mM}$ aqueous sodium hydroxide by centrifugation at 8,000g (15nm GNP), 2,000g (30nm GNP), 1,000g (60nm GNP), or 2,500g (40nm 
SNP) for 60 minutes at $4^{\circ} \mathrm{C}$ to remove reaction byproducts. Nanoparticles were concentrated by centrifugation. The supernatant was removed and the pellet was re-suspended in 40uL of water.

Procedure 5: To produce nanoparticles grafted with poly(ethylene glycol) (PEG) at high density, a 1mM stock solution of cPEG5K-SH (Laysan, cat\#:115-78), mPEG1KSH (Laysan, cat\#:102-174), mPEG20K-SH (Laysan, cat\#:110-34), mPEG2K-SH (Laysan, cat\#:103-56), mPEG5K-SH (Laysan, cat\#:115-30), or nPEG5K-SH (RAPP Polymere, cat\#:135000-40-20) was prepared in water. To produce nanoparticles grafted with PEG at low density, a 16.8uM stock solution of cPEG5K-SH, mPEG20K$\mathrm{SH}$, or nPEG5K-SH was prepared in water. A 100uL aliquot of the appropriate PEG stock was transferred to a microcentrifuge tube. For low density PEG grafting, 10uL of $3 \%(\mathrm{w} / \mathrm{v})$ aqueous sodium citrate dibasic trihydrate was added to act as a stabilizer. A $40 \mathrm{~cm}^{2}$ aliquot of the appropriate gold or silver nanoparticle core stock was centrifuged to concentrate. The supernatant was discarded and the pellet was re-suspended in 900uL water, added to the PEG, and mixed quickly with a pipette. The sample was incubated at $60^{\circ} \mathrm{C}$ for $1 \mathrm{~h}$ to complete the ligand exchange. Nanoparticles were washed once in $1 \mathrm{~mL} 0.03 \%(\mathrm{w} / \mathrm{v})$ aqueous sodium citrate tribasic dihydrate (for low density grafting) or $1 \mathrm{~mL}$ water (for high density grafting) by centrifugation for at 12,000g (15nm GNP), 3,000g (30nm GNP), 1,000g (60nm GNP), or 4,000g (40nm SNP) for 60 minutes at $4^{\circ} \mathrm{C}$. Surface-modified nanoparticles were concentrated by centrifugation. The supernatant was removed and the pellet was re-suspended in $40 \mathrm{uL}$ water.

Procedure 6: Poly(styrene-co-maleic-anhydride) (PSMA) (Sigma, cat\#:442402) was modified by a panel of aminated molecules. $6.5 \mathrm{mg}$ ethanolamine (Sigma, cat\#:398136), 6.5mg ethylenediamine (Sigma, cat\#:E26266), 8.0mg aminopropanol (Acros, cat\#:104450010), 6.3mg urea (Bioshop, cat\#:URE001.1), 14.3mg aminoacetophenone (Aldrich, cat\#:A38002), 20mg amino-PEG3K (Sigma, cat\#:07969), or 30mg amine-modified mPEG5K (Laysan, cat\#:110-130) was dissolved in 500uL N,N-dimethylformamide (DMF) (Sigma, cat\#: 227056) and 
mixed with 10mg PSMA dissolved in 500uL DMF. The mixture was incubated overnight at room temperature. 6.5mg ethanolamine in DMF was added and the mixture was incubated for $1 \mathrm{~h}$ at room temperature to complete the ring-opening reaction. Modified PSMA was stored in DMF at $-30^{\circ} \mathrm{C}$ for up to 2 weeks following synthesis. To prepare surface-modified gold or silver nanoparticles, $1 \mathrm{mg}$ of modified PSMA was transferred to a microcentrifuge tube and diluted with $1 \mathrm{~mL} 3 \mathrm{mM}$ aqueous sodium hydroxide. A $40 \mathrm{~cm}^{2}$ aliquot of the appropriate gold or silver nanoparticle core stock was centrifuged to concentrate. The supernatant was discarded and the pellet was re-suspended in 250uL DMF. 20uL 2.29mM 2napthalenethiol (Sigma, cat\#:270849) in DMF was added. The mixture was incubated for $1 \mathrm{~h}$ at $60^{\circ} \mathrm{C}$, cooled to room temperature, and added to the modified PSMA. The mixture was incubated at $60^{\circ} \mathrm{C}$ for $1 \mathrm{~h}$ to allow polymer association to the nanoparticle and then left overnight at room temperature with end-over-end rotation. The surface-modified nanoparticles were washed into $1 \mathrm{~mL} 3 \mathrm{mM}$ aqueous sodium hydroxide by centrifugation at 15,000g (15nm GNP), 3,500g (30nm GNP), 1,500g (60nm GNP), or 4,000g (40nm SNP) for 60 minutes at room temperature. Nanoparticles were washed a second time into $1 \mathrm{~mL} 3 \mathrm{mM}$ aqueous sodium hydroxide by centrifugation at 10,000g (15nm GNP), 2,500g (30nm GNP), 1,000g (60nm GNP), or 3,000g (40nm SNP) for 60 minutes at room temperature to remove remaining byproducts. The supernatant was discarded and the pellet was resuspended in 40uL water.

Procedure 7: A 50uL aliquot of 30mM L-glycine (Sigma, cat\#:G8898), 30mM Ltryptophan (Sigma, cat\#:T0254), 15mM L-asparagine (Sigma, cat\#:A0884), 30mM Lserine (Sigma, cat\#:S2600), 30mM L-alanine (Sigma, cat\#:A26802), 30mM Lphenylalanine (Sigma, cat\#:P2126), 30mM L-methionine (Sigma, cat\#:M9625), 30mM L-threonine (Sigma, cat\#:T8625), 30mM mPEG5K-NH2 (Laysan, cat\#:110130), or 30mM NH2-PEG3K-OH (Sigma, cat\#:07969) in 100mM aqueous HEPES buffer (pH 7.4) (BioShop, cat\#:HEP001.500) was mixed with 50uL 7.5mM 3,3'dithiobis(sulfosuccinimidylpropionate) (DTSSP) (Pierce, cat\#:21578) in dimethyl sulfoxide (DMSO) (Sigma, cat\#: 276855). Solutions were incubated for $1 \mathrm{~h}$ at room 
temperature and then stored at $-30^{\circ} \mathrm{C}$ until use. To prepare surface-modified nanoparticles, a $20 \mathrm{uL}$ aliquot of the appropriate DTSSP-modified molecule was transferred to a microcentrifuge tube and diluted to $100 \mathrm{uL}$ with water. A $40 \mathrm{~cm}^{2}$ aliquot of the appropriate gold or silver nanoparticle core stock was concentrated by centrifugation. The supernatant was discarded and the pellet was re-suspended in $900 \mathrm{uL}$ water before being added to the ligand aliquot. Mixtures were incubated for $1 \mathrm{~h}$ at $60^{\circ} \mathrm{C}$, and then cooled to room temperature. $10 \mathrm{uL} 300 \mathrm{mM}$ aqueous TMAH was added to each mixture to stabilize the nanoparticle suspension. Nanoparticles were washed twice into $1 \mathrm{~mL} 3 \mathrm{mM}$ aqueous TMAH by centrifugation at 8,000g (15nm GNP), 2,500g (30nm GNP), 1,000g (60nm GNP), or 2,500g (40nm SNP) for 60 minutes at room temperature to remove reaction byproducts. The supernatant was discarded and the pellet was re-suspended in $40 \mathrm{uL}$ water.

Procedure 8: A 500uL aliquot of $10 \mathrm{mg} / \mathrm{mL}$ aqueous poly-L-lysine (PLL) (Sigma, cat\#:81332), 10mg/mL aqueous poly(ethyleneimine) (PEI) (Sigma, cat\#:482595), or $10 \mathrm{mg} / \mathrm{mL}$ aqueous poly(allylamine hydrochloride) (PAH) (Sigma, cat\#:283215) was transferred to a new tube and diluted with $350 \mathrm{uL}$ water. $100 \mathrm{uL}$ of $1 \mathrm{M}$ phosphate buffer (pH 7.5) was added to the PLL or PEI aliquot. 100uL of 1M borate buffer (pH 7.5) was added to the PAH aliquot. 50uL of 36.3mM aqueous 2iminothiolane hydrochloride (Pierce, cat\#:26101) was added to the mixture. The mixture was incubated for $1 \mathrm{~h}$ at room temperature. Thiolated polymers were stored at $-30^{\circ} \mathrm{C}$ until use. To prepare nanoparticles, a $50 \mathrm{uL}$ aliquot of the appropriate thiolated polymer stock was thawed and transferred to a microcentrifuge tube. $10 \mathrm{uL}$ of $300 \mathrm{mM}$ aqueous hydrochloric acid and $40 \mathrm{uL}$ of water was added. A $40 \mathrm{~cm}^{2}$ aliquot of the appropriate gold or silver nanoparticle core stock was concentrated by centrifugation. The supernatant was discarded and the pellet was re-suspended in $800 \mathrm{uL}$ water before being added to the polymer aliquot. The solution was mixed thoroughly and incubated at $60^{\circ} \mathrm{C}$ for 1 hour before being cooled to room temperature. The mixture was centrifuged at room temperature for 60 minutes at 9,000g (15nm GNP), 3,000g (30nm GNP), 1,500g (60nm GNP), or 4,000g (40nm SNP) to pellet the surface-modified nanoparticles. The supernatant was discarded 
and the pellet was re-suspended in $1 \mathrm{~mL}$ of $3 \mathrm{mM}$ aqueous hydrochloric acid. Nanoparticles were pelleted by centrifugation. The supernatant was discarded, and the pellet was re-suspended in $40 \mathrm{uL}$ of water.

Procedure 9: A 100uL aliquot of 1\%(w/v) benzyldimethylhexadecylammonium bromide (BDHDA) (Sigma, cat\#:B4136) in ethanol, 1\%(w/v) hexadecyltrimethylammonium bromide (CTAB) (Sigma, cat\#:855820) in ethanol, 0.5\%(w/v) 1,2-dioleoyl-3-trimethylammonium-propane (Avanti Polar Lipids, cat\#:890890E) in ethanol, 0.1\%(w/v) hexadecylamine (HDA) (Sigma, cat\#:445312) in ethanol (stoichiometrically neutralized with $1 \mathrm{M}$ aqueous hydrochloric acid), 0.02\%(w/v) octadecylamine (ODA) (Sigma, cat\#:305391) in ethanol containing $3 \mathrm{mM}$ hydrochloric acid, 0.02\%(w/v) stearic acid (SA) (Sigma, cat\#:26,838-0) in ethanol containing 3mM sodium hydroxide, 1\%(w/v) aqueous sodium dodecyl sulfate (Sigma, cat\#:L3771), 1\%(w/v) aqueous Pluronic F127 (Sigma, cat\#:P2443), 1\%(w/v) sodium deoxycholate (DC) (Sigma, cat\#:30970) in ethanol containing $3 \mathrm{mM}$ sodium hydroxide, 1\%(w/v) aqueous poly(vinyl alcohol) (Sigma, cat\#:360627), 1\%(w/v) aqueous poly(vinylpyrrolidone) (Sigma, cat\#:856568), or 1\%(w/v) aqueous TWEEN20 (Sigma, cat\#:P9416) was transferred to a microcentrifuge tube. A $40 \mathrm{~cm}^{2}$ aliquot of the appropriate gold or silver nanoparticle core stock was concentrated by centrifugation. The supernatant was discarded and the pellet was re-suspended in $800 \mathrm{uL}$ water before being added to the surfactant aliquot and mixed thoroughly. For modification with 1-dodecanethiol (DDT), 10uL of 3mM DDT (Sigma, cat\#:471354) in ethanol was added to the nanoparticlesurfactant mixture. For modification with 2-napthalenethiol (NT), 10uL of 3mM NT (Sigma, cat\#:270849) in ethanol was added to the nanoparticle-surfactant mixture. The sample was mixed thoroughly and heated to $60^{\circ} \mathrm{C}$ for $1 \mathrm{~h}$, cooled to room temperature, and left overnight to ripen. To stabilize SA- or DC-modified nanoparticles, $10 \mathrm{uL}$ of $300 \mathrm{mM}$ aqueous sodium hydroxide was added. To stabilize ODA- or HDA-modified nanoparticles, 10uL 300mM aqueous hydrochloric acid was added. The sample was mixed and centrifuged at 9,000g (15nm GNP), 2,500g (30nm GNP), 1,000g (60nm GNP), or 3,500g (40nm SNP) at room temperature for 60 
minutes to pellet the surface-modified nanoparticles. The supernatant was discarded. CTAB-, ODA-, or BDHDA-modified nanoparticles were re-suspended in $1 \mathrm{~mL}$ water. All other surface-modified nanoparticles were re-suspended in $750 \mathrm{uL}$ $0.01 \%(\mathrm{w} / \mathrm{v})$ aqueous sodium citrate tribasic dihydrate. $10 \mathrm{uL} 300 \mathrm{mM}$ aqueous sodium hydroxide was added to SA- or DC-modified nanoparticles. 10uL 300mM aqueous hydrochloric acid was added was added to ODA- or HDA-modified nanoparticles. The sample was centrifuged at 7,000g (15nm GNP), 2,000g (30nm GNP), 1,000g (60nm GNP), or 2,500g (40nm SNP) for 60 minutes at room temperature to pellet the surface-modified nanoparticles. The supernatant was removed and the pellet was re-suspended in $40 \mathrm{uL}$ of water.

Procedure 10: A 100uL aliquot of 0.1\%(w/v) dodecylamine (DDA) in ethanol was transferred to a microcentrifuge tube. $10 \mathrm{uL}$ of $300 \mathrm{mM}$ aqueous hydrochloric acid was added to the DDA aliquot. A $40 \mathrm{~cm}^{2}$ aliquot of the appropriate gold or silver nanoparticle core stock was concentrated by centrifugation. The supernatant was discarded and the pellet was re-suspended in 900uL water, added to the DDA aliquot, and mixed rapidly. Samples were incubated at room temperature for 30 minutes to allow DDA association to the nanoparticle core. $100 \mathrm{uL}$ of $30 \mathrm{mM} 6$ amino-1-hexanethiol (Sigma, cat\#:733679) in ethanol, or 30mM 11-amino-1undecanethiol (Dojindo, cat\#:A423) in ethanol was rapidly added to the nanoparticle-DDA mixture. The mixture was vortexed and heated to $60^{\circ} \mathrm{C}$ for $1 \mathrm{~h}$ and then cooled to room temperature. Samples were centrifuged at 8,500g (15nm GNP), 2,500g (30nm GNP), 1,000g (60nm GNP), or 3,500g (40nm SNP) for 60 minutes at room temperature to pellet the surface-modified nanoparticles. The supernatant was discarded and the pellet was re-suspended in $1 \mathrm{~mL} 3 \mathrm{mM}$ aqueous hydrochloric acid. The sample was centrifuged to pellet the surface-modified nanoparticles. The supernatant was discarded and the pellet was re-suspended in $40 \mathrm{uL}$ water.

\section{Serum incubation, washing, and protein isolation}

Human serum (HS) (Sigma, cat\#:H4522) was pooled over multiple donors to minimize inter-individual variability. Aliquots of $\mathrm{HS}$ were preserved at $-30^{\circ} \mathrm{C}$ until 
use. Prior to use, aliquots of HS were thawed and filtered using $0.22 \mathrm{um}$ polyethersulfone syringe filters (Millipore, cat\#:SLGP033RS). Filtered HS was transferred to a microcentrifuge tube. Nanoparticles were added to the HS and mixed rapidly. Volumes of nanoparticles and HS were chosen to give 10uL HS per $\mathrm{cm}^{2}$ of nanoparticle surface area. Nanoparticles were incubated with HS for $1 \mathrm{~h}$ at $37^{\circ} \mathrm{C}$ to allow protein association. $1 \mathrm{~h}$ was chosen to allow the composition of the protein corona to reach a quasi-equilibrium state and to simulate the composition of the protein corona likely to be encountered by cells in vivo. ${ }^{70}$ Each experiment included a 'washing control' consisting of an aliquot of HS without nanoparticles. The washing control accounts for the carry-over of unbound proteins that may interfere with subsequent analyses. Following incubation, nanoparticle-HS mixtures and the washing control were centrifuged at 15,000g (15nm GNP), 4,500g (30nm GNP), 1,500g (60nm GNP), or 5,000g (40nm SNP) for 45 minutes at $4{ }^{\circ} \mathrm{C}$. Centrifugation was performed at $4^{\circ} \mathrm{C}$ to minimize protein desorption. The supernatant containing unbound protein was discarded and the pellet was resuspended in 10mM phosphate buffered saline (PBS) (pH 7.5) (Wisent, cat\#:311420-CL) supplemented with 0.05\%(w/v) TWEEN20 (Sigma, cat\#:P9416). Aliquots were drawn and analyzed by dynamic light scattering and absorbance spectrophotometry (see below). The remaining nanoparticles were washed once in PBS supplemented with TWEEN20 and once in PBS without TWEEN20 to remove remaining unbound serum proteins. Following the last washing step, nanoparticles were concentrated by centrifugation and the supernatant was discarded. $8 \mathrm{uL}$ of $4 \mathrm{X}$ LDS sample buffer (Invitrogen, cat\#:NP0008) and 4uL of 500mM aqueous DLdithiothreitol (DTT) (BioShop, cat\#:DTT001.5) was added to each sample. Samples were incubated at $70^{\circ} \mathrm{C}$ for 60 minutes to strip bound serum protein. Samples were centrifuged at room temperature for 15 minutes at 15,000g to pellet aggregated nanoparticles. Supernatants containing isolated proteins were collected and stored at $-30^{\circ} \mathrm{C}$ for further analysis.

\section{Dynamic light scattering (DLS)}

A $5 \mathrm{uL}$ aliquot of each surface-modified gold or silver nanoparticle stock was diluted 
to $400 \mathrm{uL}$ with water in a $1.5 \mathrm{~mL}$ polystyrene cuvette (BioMart, cat\#:B1022-PS). A $5 \mathrm{uL}$ aliquot of each nanoparticle exposed to human serum (HS) was diluted to 400uL with PBS (Wisent, cat\#:311-420-CL). PBS was chosen as a diluent to avoid changing the ionic strength of the solution, which can lead to changes in protein conformation, desorption, and nanoparticle aggregation. Each sample was characterized using the ZetaSizer Nano ZS (Malvern Instruments). The attenuator position was set to $4.65 \mathrm{~mm}$ and the attenuation was set automatically based on the size and concentration of the nanoparticle sample. The z-average hydrodynamic diameter (HD), intensity mean HD, number mean HD, volume mean HD, and polydiserpsity index (PDI) of each sample was computed using the manufacturer's software. To characterize zeta potential of each nanoparticle sample, aliquots of surface-modified gold or silver nanoparticle stocks were diluted in $1 \mathrm{~mL} 10 \mathrm{mM}$ aqueous HEPES (pH 7.4) containing $1 \mathrm{mM}$ sodium chloride and transferred to a 4.5mL polystyrene cuvette (BioMart, B1021-PS). Nanoparticles exposed to HS (1h @ $37^{\circ} \mathrm{C}$ ) were diluted in PBS and transferred to a polystyrene cuvette. A dip cell was inserted into the cuvette and measurements were collected using the ZetaSizer Nano ZS. The mean zeta potential for each formulation was computed using the manufacturer's software.

\section{Absorbance spectrophotometry (AS)}

Samples prepared for DLS (see above) were diluted to $1 \mathrm{~mL}$ with either water (for synthesized) or phosphate buffered saline (PBS) (for serum-exposed). Absorbance spectra were collected from 450nm to 950nm using the UV-1601PC absorbance spectrophotometer (Shimadzu). The localized surface plasmon resonance index (LSPRi) for each formulation was computed in Excel (Microscoft). LSPRi is an empirical measure of the local dielectric environment surrounding plasmonic nanoparticles. ${ }^{71,72}$ The LSPRi for gold nanoparticles is defined as follows:

$$
\mathrm{LSPRi}=\frac{\sum_{\lambda=580}^{\lambda=900} \mathrm{OD}(\lambda)}{\sum_{\lambda=450}^{\lambda=900} \mathrm{OD}(\lambda)}(15 \mathrm{~nm} \mathrm{GNP})
$$




$$
\begin{aligned}
& \text { LSPRi }=\frac{\sum_{\lambda=590}^{\lambda=900} \mathrm{OD}(\lambda)}{\sum_{\lambda=450}^{\lambda=900} \mathrm{OD}(\lambda)}(30 \mathrm{~nm} \text { GNP }) \\
& \mathrm{LSPRi}=\frac{\sum_{\lambda=600}^{\lambda=900} \mathrm{OD}(\lambda)}{\sum_{\lambda=400}^{\lambda=900} \mathrm{OD}(\lambda)}(60 \mathrm{~nm} \mathrm{GNP})
\end{aligned}
$$

Where $\operatorname{OD}(\lambda)$ is the optical density of the nanoparticle solution at wavelength ' $\lambda$ '.

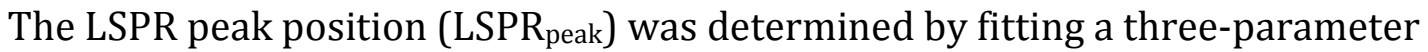
Gaussian function to the absorbance spectrum.

\section{Ellman depletion assay}

The Ellman depletion assay was performed as described previously ${ }^{32}$, with minor modifications. Briefly, stock solutions of MUA, MBA, MHA, MAA, MSA, MPA, MUTA, MES, AC, TP, AHT, glutathione (GSH) (Sigma, cat\#:G4251), penicillamine (PCA) (Sigma, cat\#:P4875), and cysteine (Sigma, cat\#:C7352) were prepared at 9mM in ethanol or water. For each ligand, 4.7pmol 15nm GNPs, 1.175pmol 30nm GNPs, and $0.31 \mathrm{pmol} 60 \mathrm{~nm}$ GNPs were washed into $90 \mu \mathrm{L}$ water by centrifugation. $10 \mu \mathrm{L}$ aliquots of ligand stock were added to microcentrifuge tubes. GNPs or an equal volume of water (control) was added to the ligand aliquots and incubated at $60^{\circ} \mathrm{C}$ for $1 \mathrm{~h}$. Samples were centrifuged at $12,000 \mathrm{~g}$ for $1 \mathrm{~h}$ to pellet nanoparticles. Supernatants were mixed with aliquots of a $10 \mathrm{mM}$ aqueous solution of Ellman's reagent (5,5'-dithiobis-(2-nitrobenzoic acid)) (Pierce, cat\#:22582) and incubated for 10 minutes at room temperature. Reduction of Ellman's reagent was quantified by measuring the absorbance at $412 \mathrm{~nm}$ and normalized to a glutathione standard. The surface density of each ligand was calculated by subtracting the concentration of unbound thiols in the sample supernatant from the control supernatant and dividing by the total nanoparticle surface area.

\section{Poly(acrylamide) gel electrophoresis (PAGE)}

PAGE was performed as described previously ${ }^{22}$, without modification. 


\section{Protein precipitation and cleanup}

A multi-step precipitation procedure was developed to eliminate detergents and reducing agents from the serum protein isolates. Protein isolates in LDS and DTT (see above) were mixed with 10\%(w/v) trichloroacetic acid (TCA) (Sigma, cat\#:T9159) in acetone (Sigma, cat\#:650501) and incubated overnight at $-80^{\circ} \mathrm{C}$. Samples were centrifuged at $4^{\circ} \mathrm{C}$ for 35 minutes at $15,000 \mathrm{~g}$ to pellet precipitates. The supernatant was discarded and the pellet was re-suspended in 500uL 0.03\%(w/v) aqueous sodium deoxycholate (Sigma, cat\#:30970). 100uL 72\%(w/v) aqueous TCA was added. The solution was vortexed to mix, and incubated on ice for $1 \mathrm{~h}$ to re-precipitate the protein. The sample was centrifuged at $4^{\circ} \mathrm{C}$ for 15 minutes at $18,000 \mathrm{~g}$ to pellet precipitates. The supernatant was carefully removed to avoid disturbing the pellet. The pellet was re-suspended in $1 \mathrm{~mL}$ cold acetone and incubated at $-80^{\circ} \mathrm{C}$ for $1 \mathrm{~h}$. The solution was centrifuged at $4^{\circ} \mathrm{C}$ for 15 minutes at $18,000 \mathrm{~g}$ to concentrate. The supernatant was discarded and the pellet was air dried for 15 minutes to remove excess acetone. Pellets were stored at $-30^{\circ} \mathrm{C}$.

\section{Bicinchoninic acid (BCA) assay}

After precipitation, protein pellets were dissolved in $25 \mathrm{uL} 2 \%(\mathrm{w} / \mathrm{v})$ sodium dodecyl sulfate (SDS) in PBS. In parallel, a bovine serum albumin (BSA) standard was prepared in 2\%(w/v) SDS in PBS. Both the samples and standards were incubated at $70^{\circ} \mathrm{C}$ for 30 minutes to solubilize and denature the protein. $600 \mathrm{uL}$ of BCA working reagent (Pierce, cat\#:23225) was added to each sample. Samples were incubated at $60^{\circ} \mathrm{C}$ for 60 minutes, or until color development was sufficient. The samples were cooled to room temperature, transferred to a 96-well plate, and characterized using an absorbance plate reader (Tecan Sunrise). Protein content in each sample was estimated by comparison to the BSA standard.

\section{Liquid chromatography tandem mass spectrometry (LC-MS/MS)}

Sample preparation: We developed a solution-based digestion protocol for serum protein isolates. As opposed to conventional strategies that rely on fractionation by PAGE, followed by band excision and in-gel digestion, the solution-based digestion 
protocol allowed us to characterize the composition of the serum protein corona in a single LC-MS/MS run. Protein pellets following precipitation and cleanup were solubilized in 45uL 100mM aqueous ammonium bicarbonate (Sigma, cat\#:A6141) and $5 \mathrm{uL}$ acetonitrile. 5uL 100mM DTT in $100 \mathrm{mM}$ ammonium bicarbonate was added to each sample. Samples were incubated at $37^{\circ} \mathrm{C}$ for 60 minutes to reduce disulfide bonds. 5uL 500mM iodoacetamide (Sigma, cat\#:I6125) in 100mM ammonium bicarbonate was added. Samples were incubated for 60 minutes in the dark to alkylate reduced disulfides. 2 ug of proteomics grade trypsin (Sigma, cat\#:T6567), dissolved in 1mM aqueous hydrochloric acid was added. Samples were incubated overnight at room temperature to complete proteolytic digestion. Digestion was halted by adding 5uL 20\%(v/v) formic acid (Sigma, cat\#:F0507). Protein digests were stored at $-30^{\circ} \mathrm{C}$ until characterization by LC-MS/MS.

LC-MS/MS and database searching: LC-MS/MS data acquisition and subsequent database searching were performed on a hybrid Orbitrap-Velos mass spectrometer (Thermo) as described previously ${ }^{22}$ with the following modifications: a $5 \mathrm{uL}$ sample injection volume, a 60 minute elution gradient, 16 data-dependent ms/ms scans per full scan mass spectrum, and duplicate wash steps between samples. To validate the relative quantification of proteins within a complex mixture, trypsin digests of the Universal Protein Standard 2 (UPS2) mixture (Sigma, cat\#:UPS2-1SET) were run using the same protocol (Fig. S9).

Post-processing: 785 unique proteins were identified across all nanoparticle formulations. Observed spectral count data for each of these proteins for each formulation is reported in the Supplementary Database. On average, 1709 \pm 703 spectral counts were recorded for each formulation. Identified serum proteins with fewer than 10 spectral counts on at least one formulation were eliminated, as were proteins that were identified on only a single formulation. Using spectral counting to estimate the relative abundance of low-abundance proteins within complex mixtures is inaccurate. The pruning procedure eliminated 656 low abundance proteins. Together, the 129 remaining proteins defined the serum protein 
fingerprint. The $\%(\mathrm{w} / \mathrm{w})$ relative abundance of each of these proteins on a given formulation was estimated using the following formula:

$$
\operatorname{RA}(n)_{\%(w / w)}=\frac{\operatorname{SpC}(n)}{\sum_{i=1}^{129} \operatorname{SpC}(i)}
$$

where $\operatorname{RA}(n)_{\%(w / w)}$ is the relative abundance of protein ' $n$ '. $\operatorname{SpC}(i)$ is the total number of spectral counts recorded for protein ' $i$ '. The sum of the relative abundances of all proteins over a given nanoparticle formulation is 1 .

The overall similarity in two protein coronas formed around two distinct nanoparticle formulations: ' $a$ ' and ' $b$ ', was calculated using the '\% overlap' parameter defined as:

$$
\% \text { overlap }=\frac{\sum_{i=1}^{129}\left(2 \times \min \left(\mathrm{RA}_{a}(i), \mathrm{RA}_{b}(i)\right)\right)}{\sum_{i=1}^{129}\left(\mathrm{RA}_{a}(i)+\mathrm{RA}_{b}(i)\right)}
$$

Global variation in the serum protein corona across independent experimental replicates was estimated using the '\% overlap' between LC-MS/MS characterizations of the serum protein corona formed around independentlyprepared 15nm citrate-stabilized gold nanoparticle samples (Fig. S11).

Gene ontology term screening: Identified proteins were screened for their involvement in five major biological processes in serum: coagulation, complement activation, lipid transport, inflammation, and cell association. Parent gene ontology (GO) terms were defined for each biological process (table S4). G0 terms assigned to each identified protein within the GO database were screened against the parent GO terms for each biological process or any of their child terms. If a match is found, the identified protein is considered to participate in that biological process. The screening algorithm was implemented in Matlab (Mathworks).

\section{Nanoparticle-cell association}


A549 human lung epithelial carcinoma cells (ATCC) were maintained in RPMI1640 (Wisent, cat\#: 350-000-CL) supplement with 10\%(v/v) fetal bovine serum (FBS) (Gibco, cat\#:12483-020) and 1\%(v/v) penicillin-streptomycin (P-S) (Gibco, cat\#:15140-122) in a sterile 5\% CO2 atmosphere in $175 \mathrm{~cm}^{2}$ tissue culture flasks (NEST, cat\#:709003). When cells reached $~ 90 \%$ confluence, they were detached using 0.25\% trypsin-EDTA (Gibco, cat\#:25200-114) and collected in fresh culture media supplemented with FBS. For cell association studies, harvested A549 cells were plated onto 24-well plates at $\sim 200,000$ cells/well and incubated overnight at $37^{\circ} \mathrm{C}$ to reach $\sim 80 \%$ confluence. Cells were handled using aseptic techniques at all stages to avoid contamination. $20 \mathrm{~cm}^{2}$ aliquots of the appropriate surface-modified gold or silver nanoparticle formulation were rapidly added to $200 \mathrm{uL} 100 \%$ human serum (HS). As a nanoparticle-free control, $20 \mathrm{uL}$ sterile water was added to $200 \mathrm{uL}$ $100 \%$ HS. Samples were incubated for $1 \mathrm{~h}$ at $37^{\circ} \mathrm{C}$, and diluted with $800 \mathrm{uL}$ RPMI1640 (without additives). A 100uL aliquot of the nanoparticles was reserved to assess total gold concentration in the incubation media. The growth media was then aspirated from wells containing cells. Wells were washed once with RPMI-1640 (without additives). 750uL RPMI-1640 (without additives) was added to each well followed by $750 \mathrm{uL}$ of the nanoparticle suspension or the control. Nanoparticles were incubated with cells for $4 \mathrm{~h}$ at $37^{\circ} \mathrm{C}$. Following incubation, cells in each well were washed four times with sterile PBS (Wisent, cat\#:311-425-CL) supplemented with $0.133 \mathrm{~g} / \mathrm{L}$ calcium chloride dihydrate (BioShop, cat\#:CCL302.500) and $0.1 \%(\mathrm{w} / \mathrm{v})$ bovine serum albumin (Sigma, cat\#:A9418) to remove particles that were free in solution and/or not strongly associated with the cell surface. The remaining PBS buffer was aspirated, and 200uL 70\% nitric acid and $20 \mathrm{uL}$ hydrochloric acid was added to each well. Cells were digested for $1 \mathrm{~h}$ at room temperature. Solutions were diluted in water (1:19) containing $100 \mathrm{uL} 100 \mathrm{ug} / \mathrm{mL}$ yttrium as an internal control. Total gold (or silver), magnesium, and yttrium content in each sample was quantified by inductively coupled plasma-atomic emission spectroscopy (ICP-AES) (Perkin-Elmer). Total cell number was calculated by comparing total magnesium content to a standard containing a known number of cells. ${ }^{73}$ Total cell association $(y)$ was calculated using the following pseudo-partition 
coefficient:

$$
y=\frac{m_{\text {cell }} / m_{\text {well }}}{m_{\text {cells }}}
$$

Where $m_{\text {cell }}$ is the total atomic gold (or silver) content associated with cells, $m_{\text {well }}$ is the total atomic gold (or silver) content in well (associated with cells and free in solution), and $m_{\text {cells }}$ is the total mass of magnesium per sample. $m_{\text {well }}$ was standardized between all treatment conditions to facilitate comparison. Cell association results for each formulation are reported in the supplementary database. Cell association was $\log _{2}$-transformed prior to model fitting.

\section{Hyaluronan inhibition}

A549 cells were plated on 12-well tissue-culture plates and grown to approximately 90\% confluence in RPMI1640 containing FBS and P-S. MUA-, MUTA-, and AUTmodified 15nm gold nanoparticles were incubated with 100\% human serum, washed in PBS to remove unbound protein, and transferred to RPMI1640 media (without additives). Free hyaluronic acid (Sigma, cat\#:H5388) in PBS was mixed with the nanoparticles and incubated for $30 \mathrm{~min}$ at room temperature. The nanoparticle-hyaluronic acid mixtures in serum-free RPMI1640 were added to A549 cells and incubated at $37^{\circ} \mathrm{C}$ for $4 \mathrm{~h}$. Net cell association was quantified using ICP-AES, as described above.

\section{Model training and validation}

Model creation is divided into two phases: 'training' and 'validation'. During the training phase, the relevant parameters of each model are fit using a set of nanoparticles with measured cell association. During the validation phase, the capacity of each model to predict the cell association of nanoparticle formulations that were not included in the training phase is assessed.

Single parameter models: A series of 129 single-parameter linear models were 
created that describe net A549 cell association of the gold nanoparticle library as a function of the relative abundance of each protein within the serum protein fingerprint. Each model has the form described in eq. 1 (see text). The model was fit using simple linear regression, meaning that $a_{j}$ was chosen to minimize the sum of squared residuals $(R S S)$ :

$$
R S S=\sum_{i=1}^{84}\left(\log _{2}\left(y_{i}\right)-\log _{2}\left(\hat{y}_{i}\right)\right)^{2}
$$

where $y_{i}$ is the measured value of cell association for formulation ' $i$ '. $\log _{2}(y)$ and $x_{j}$ were mean-centered and variance scaled prior to model fitting.

The statistical significance of each model was determined using the 'CVANOVA' technique. ${ }^{74}$ This technique uses an $F$-test to determine whether the model has prediction residuals (from cross-validation) that are significantly smaller than the variation of each $y_{i}$ around the mean value of $y_{i}$. Models were considered statistically significant if $p<0.05$.

Multi-parametric models: Multi-parametric linear models were created that express cell association as a function of $m$ parameters describing each of $n$ nanoparticle formulations. Each model has the form described in eq. 2. In matrix notation, eq. 2 can be expressed as:

$$
\widehat{\mathbf{Y}}=\mathbf{X b}
$$

where $\widehat{\mathbf{Y}} \in \mathbf{R}^{n \times 1}, \mathbf{X} \in \mathbf{R}^{n \times m}$, and $\mathbf{b} \in \mathbf{R}^{m \times 1} . \widehat{\mathbf{Y}}$ is a vector of cell association values for each formulation within the nanoparticle library, $\mathbf{b}$ is a vector of model coefficients, and $\mathbf{X}$ is a matrix of parameter values for each formulation. The parameter $n$ is the total number of nanoparticle formulations within the library. The form of $\mathbf{X}$ depends on the parameter set used to describe each formulation within the nanoparticle library. For models that use the serum protein fingerprint to describe the gold nanoparticle library, $\mathbf{X} \in \mathbf{R}^{84 \times 129}$, where each row of $\mathrm{X}$ is a 129-element vector of 
the relative abundances of each protein within the serum protein fingerprint on that formulation. For models that use parameter sets derived from DLS, ZP, AS, TEM, and BCA measurements to describe the gold nanoparticles, $\mathbf{X} \in \mathbf{R}^{84 \times 11}, \mathbf{X} \in \mathbf{R}^{84 \times 14}$, $\mathbf{X} \in \mathbf{R}^{84 \times 11}, \mathbf{X} \in \mathbf{R}^{84 \times 1}$, and $\mathbf{X} \in \mathbf{R}^{84 \times 1}$, respectively. Parameters within each of these sets represent primary measurements and/or combinations of primary measurements. A description of each parameter is provided in table S9.

During model training, partial least squares regression (PLSR) was used to compute 'b' for each model. In the PLSR procedure, the dependent cell response vector $(\mathbf{Y})$ is expressed as a linear combination of the independent parameter matrix (X) within an orthonormal latent variable space known as the 'principal component' (PC) space. The PLSR projections onto the PC space are computed to maximize the covariance between $\mathbf{X}$ and $\mathbf{Y}$ within the PC space. PCs are computed and extracted iteratively as described elsewhere. ${ }^{75}$ Lower order PCs contain most of the information in the original dataset that is useful for explaining the variance in $\mathbf{Y}$. As a result, higher order PCs can be ignored without a significant loss of model accuracy. For each parameter set, the optimal number of PCs included during model training was determined by cross-validation. Values of $b_{j}$ were transformed from the PC space into the parameter space. Prior to model training, $X$ and Y were mean subtracted and variance scaled.

During the PLSR modeling procedure, a parameter reduction procedure was used to iteratively remove parameters with low relevance to the model. The optimal number of parameters was chosen by jackknifing. ${ }^{54}$ Briefly, a model was fit by PLSR using the full parameter set. Then, the parameter with the lowest relevance to the model, as determined by the variable importance to the projection (VIP), was iteratively removed and a new model was created using the reduced parameter set. The optimal parameter subset was determined by cross-validation. This procedure was also used to estimate model accuracy using a pre-defined number of parameters.

To predict the cell association of silver nanoparticle formulations, three distinct models were created. The first was trained using gold nanoparticle 
formulations only. The cell association of the silver nanoparticles was predicted as a 'external' set of nanoparticles. The second was trained using both gold nanoparticles and silver nanoparticles together. The third model was trained using only silver nanoparticles. For the second and third model, the cell association of the silver nanoparticles was predicted using leave-one-out cross validation.

The statistical significance of each model was assessed using CV-ANOVA (see above).

Model validation: The accuracy of each model was assessed using the coefficient of determination $\left(\mathrm{R}^{2}\right)$ between the measured value of cell association for each nanoparticle formulation and the value that is estimated from the model. $\mathrm{R}^{2}$ is defined as:

$$
R^{2}=1-\frac{\sum_{i=1}^{n}\left(y_{i}-\hat{y}_{i}\right)^{2}}{\sum_{i=1}^{n}\left(y_{i}-\tilde{y}\right)^{2}}
$$

where $\tilde{y}$ is the mean measured cell association.

The predictive capacity of each model was assessed using 'leave-one-out' cross validation. For this procedure, each formulation is iteratively removed from the dataset and a new model is trained using the reduced dataset. The resulting model is then used to predict the cell association of the formulation that was withheld. The coefficient of determination under leave-one-out cross validation $\left(\mathrm{Q}^{2} \mathrm{LOO}\right)$ is defined as:

$$
Q_{L O O}^{2}=1-\frac{\sum_{i=1}^{n}\left(y_{i}-\hat{y}_{(L O O) i}\right)^{2}}{\sum_{i=1}^{n}\left(y_{i}-\tilde{y}\right)^{2}}
$$

where $\hat{y}_{(L O O) i}$ is the cell association value of formulation ' $i$ ' estimated during crossvalidation. Models with $Q_{L O O}^{2}>0.7$ are considered good. 55

We performed 'leave-many-out' cross validation as a more stringent test of predictive capacity. In this procedure, $25 \%$ of the formulations within the dataset 
are randomly and repeatedly withheld from the dataset. A new model is trained using the remaining $75 \%$ of the formulations. This new model is used to predict the cell association of the withheld formulations. The coefficient of determination between the measured and predicted values of cell association $\left(Q_{L M O 25 \%}^{2}\right)$ was computed for each iteration. This procedure was repeated 100 times for each model. Values of $Q_{L M O 25 \%}^{2}$ are reported as the mean \pm SD over all iterations.

Applicability domain: The applicability domain, also known as the optimum prediction space, of each model was assessed using the standardized cross-validated residual $(\varepsilon)$ and 'leverage' $(h) .14,76,77$ The standardized cross-validated residual is defined for formulation ' $i$ ' as:

$$
\varepsilon_{i}=\frac{\hat{y}_{(L O O) i}-y_{i}}{S^{2}}
$$

where $S^{2}$ is the sample variance of $\varepsilon_{i}$ across all formulations. $\varepsilon_{i}$ characterizes the accuracy of the model estimate of cell association for formulation ' $i$ ' relative to the model estimates for all other formulations. A formulation is considered an outlier if the absolute value of $\varepsilon_{i}$ is greater than 3 .

The leverage value measures the distance of each formulation to the center of mass of the distribution within the parameter space. The value of $h$ for formulation $i$ is defined as:

$$
h=\mathbf{x}_{i}^{T}\left(\mathbf{X}^{T} \mathbf{X}\right)^{-1} \mathbf{x}_{i}
$$

where $x_{i}$ is a vector of parameter values for formulation ' $i$ ' (in the PC space), and $\mathbf{X}$ is a matrix of parameter values for all formulations. A formulation has a disproportionately large influence on the resulting model, and is thus considered an outlier, if its leverage value is above the warning level, defined as:

$$
h^{*}=\frac{3(p+1)}{n}
$$




\begin{abstract}
Where $p$ is the number of principal components used during model training, and $n$ is the number of formulations. $\varepsilon_{i}$ and $h$ for each formulation are visually represented using a Williams plot.
\end{abstract}


Author Contributions. W.C.W.C. and C.D.W. planned the study and wrote the manuscript. Y.C. and A.E. contributed to study design and provided materials. C.D.W. and F.S. synthesized nanoparticles. C.D.W., F.S., and D.W.O. prepared samples, performed DLS, ZP, AS, and BCA characterization, and cell association studies. C.D.W., J.B.O. and H.G. performed LC-MS/MS and analyzed data. C.D.W. and R.L. analyzed data and performed model training and validation. All authors discussed the results and commented on the manuscript.

Acknowledgements. WCW acknowledges the Canadian Institute of Health Research (RMF-111623; COP-126588), Naturals Science and Engineering Research Council (NSERC; NETGP35015; RGPIN-288231; CRDPJ424710), Canadian Foundation for Innovation, and Canadian Research Chair's Program for research support. AE acknowledges Ontario Ministry of Research and Innovation (ORF-GL2). YC acknowledges the US National Science Foundation and Environmental Protection Agency to the UCLA Center for Environmental Implications of Nanotechnology. CDW and JO acknowledge NSERC and Ontario Graduate Scholarship, respectively, for graduate fellowship.

Supporting Information Available: Supplementary figures, and supplementary tables, and a Supplementary Database of measurements performed in this study are provided. This material is available free of charge via the Internet at http://pubs.acs.org

\section{References:}

1. Xia, Y.; Xiong, Y.; Lim, B.; Skrabalak, S. E. Shape-Controlled Synthesis of Metal Nanocrystals: Simple Chemistry Meets Complex Physics? Angew. Chem., Int. Ed. 2009, 48, 60-103.

2. Murray, C. B.; Kagan, C. R.; Bawendi, M. G. Synthesis and Characterization of Monodisperse Nanocrystals and Close-Packed Nanocrystal Assemblies. Annu. Rev. Mater. Sci. 2000, 30, 545-610.

3. Jain, P. K.; Lee, K. S.; El-Sayed, I.; El-Sayed, M. Calculated Absorption and Scattering Properties of Gold Nanoparticles of Different Size, Shape, and Composition: Applications in Biological Imaging and Biomedicine. J. Phys. Chem. B 2006, 110, 7238-7248.

4. Kim, B. Y. S.; Rutka, J. T.; Chan, W. C. W. Current Concepts: Nanomedicine. N. Engl. J. Med. 2010, 363, 2434-2443.

5. Shulaker, M. M.; Hills, G.; Patil, N.; Wei, H.; Chen, H.-Y.; Wong, H.; Mitra, S. Carbon Nanotube Computer. Nature 2013, 501, 526-530. 
6. Qian, L.; Zheng, Y.; Xue, J.; Holloway, P. H. Stable and Efficient Quantum-Dot LightEmitting Diodes Based on Solution-Processed Multilayer Structures. Nat. Photonics 2011, 5, 543-548.

7. Tassa, C.; Shaw, S. Y.; Weissleder, R. Dextran-Coated Iron Oxide Nanoparticles: A Versatile Platform for Targeted Molecular Imaging, Molecular Diagnostics, and Therapy. Acc. Chem. Res. 2011, 44, 842-852.

8. Nel, A.; Xia, T.; Meng, H.; Wang, X.; Lin, S.; Ji, Z.; Zhang, H. Nanomaterial Toxicity Testing in the 21st Century: Use of a Predictive Toxicological Approach and HighThroughput Screening. Acc. Chem. Res. 2013, 46, 607-621.

9. $\quad$ Rivera-Gil, P.; Aberasturi, J. D.; Wulf, V.; Pelaz, B.; Del Pino, P.; Zhao, Y.; Fuente, D. L.; Larramendi, R. D.; Rojo, T.; Liang, X. J., et al. The Challenge to Relate the Physicochemical Properties of Colloidal Nanoparticles to Their Cytotoxicity. Acc. Chem. Res. 2013, 46, 743749.

10. Pokhrel, S.; Nel, A. E.; Mädler, L. Custom-Designed Nanomaterial Libraries for Testing Metal Oxide Toxicity. Acc. Chem. Res. 2013, 46, 632-641.

11. Soenen, S. J.; Rivera-Gil, P.; Montenegro, J. M.; Parak, W. J.; De Smedt, S. C.; Braeckmans, K. Cellular Toxicity of Inorganic Nanoparticles: Common Aspects and Guidelines for Improved Nanotoxicity Evaluation. Nano Today 2011, 6, 446-465.

12. Khlebtsov, N.; Dykman, L. Biodistribution and Toxicity of Engineered Gold Nanoparticles: A Review of in vitro and in vivo Studies. Chem. Soc. Rev. 2011, 40, 1647-1671. 13. Shaw, S. Y.; Westly, E. C.; Pittet, M. J.; Subramanian, A.; Schreiber, S. L.; Weissleder, R. Perturbational Profiling of Nanomaterial Biologic Activity. Proc. Natl. Acad. Sci. U. S. A. 2008, 105, 7387-7392.

14. Puzyn, T.; Rasulev, B.; Gajewicz, A.; Hu, X.; Dasari, T. P.; Michalkova, A.; Hwang, H. M.; Toropov, A.; Leszczynska, D.; Leszczynski, J. Using Nano-Qsar to Predict the Cytotoxicity of Metal Oxide Nanoparticles. Nat. Nanotechnol. 2011, 6, 175-178.

15. Zhang, H.; Ji, Z.; Xia, T.; Meng, H.; Low-Kam, C.; Liu, R.; Pokhrel, S.; Lin, S.; Wang, X.; Liao, Y. P., et al. Use of Metal Oxide Nanoparticle Band Gap to Develop a Predictive Paradigm for Oxidative Stress and Acute Pulmonary Inflammation. ACS Nano 2012, 6, 4349-4368.

16. Liu, R.; Rallo, R.; George, S.; Ji, Z.; Nair, S.; Nel, A. E.; Cohen, Y. Classification Nanosar Development for Cytotoxicity of Metal Oxide Nanoparticles. Small 2011, 7, 1118-1126.

17. Fourches, D.; Pu, D.; Tassa, C.; Weissleder, R.; Shaw, S. Y.; Mumper, R. J.; Tropsha, A. Quantitative Nanostructure-Activity Relationship Modeling. ACS Nano 2010, 4, 5703-5712. 18. Puzyn, T.; Leszczynska, D.; Leszczynski, J. Toward the Development of "Nano-Qsars": Advances and Challenges. Small 2009, 5, 2494-2509.

19. Epa, V. C.; Burden, F. R.; Tassa, C.; Weissleder, R.; Shaw, S.; Winkler, D. A. Modeling Biological Activities of Nanoparticles. Nano Lett. 2012, 12, 5808-5812.

20. Monopoli, M. P.; Åberg, C.; Salvati, A.; Dawson, K. A. Biomolecular Coronas Provide the Biological Identity of Nanosized Materials. Nat. Nanotechnol. 2012, 7, 779-786.

21. Cedervall, T.; Lynch, I.; Lindman, S.; Berggård, T.; Thulin, E.; Nilsson, H.; Dawson, K. A.; Linse, S. Understanding the Nanoparticle-Protein Corona Using Methods to Quantify Exchange Rates and Affinities of Proteins for Nanoparticles. Proc. Natl. Acad. Sci. U. S. A. 2007, 104, 2050-2055. 
22. Walkey, C. D.; Chan, W. C. W. Understanding and Controlling the Interaction of Nanomaterials with Proteins in a Physiological Environment. Chem. Soc. Rev. 2012, 41, 2780-2799.

23. Deng, Z. J.; Liang, M.; Toth, I.; Monteiro, M. J.; Minchin, R. F. Molecular Interaction of Poly(Acrylic Acid) Gold Nanoparticles with Human Fibrinogen. ACS Nano 2012, 6, 89628969.

24. Monopoli, M. P.; Walczyk, D.; Campbell, A.; Elia, G.; Lynch, I.; Baldelli Bombelli, F.; Dawson, K. A. Physical-Chemical Aspects of Protein Corona: Relevance to in vitro and in vivo Biological Impacts of Nanoparticles. J. Am. Chem. Soc. 2011, 133, 2525-2534.

25. Walczyk, D.; Bombelli, F. B.; Monopoli, M. P.; Lynch, I.; Dawson, K. A. What the Cell "Sees" in Bionanoscience. J. Am. Chem. Soc. 2010, 132, 5761-5768.

26. Lesniak, A.; Fenaroli, F.; Monopoli, M. P.; Åberg, C.; Dawson, K. A.; Salvati, A. Effects of the Presence or Absence of a Protein Corona on Silica Nanoparticle Uptake and Impact on Cells. ACS Nano 2012, 6, 5845-5857.

27. Ge, C.; Du, J.; Zhao, L.; Wang, L.; Liu, Y.; Li, D.; Yang, Y.; Zhou, R.; Zhao, Y.; Chai, Z., et al. Binding of Blood Proteins to Carbon Nanotubes Reduces Cytotoxicity. Proc. Natl. Acad. Sci. U. S. A. 2011, 108, 16968-16973.

28. Schanen, B. C.; Karakoti, A. S.; Seal, S.; Drake Iii, D. R.; Warren, W. L.; Self, W. T. Exposure to Titanium Dioxide Nanomaterials Provokes Inflammation of an in vitro Human Immune Construct. ACS Nano 2009, 3, 2523-2532.

29. Jones, C. F.; Grainger, D. W. In vitro Assessments of Nanomaterial Toxicity. Adv. Drug Delivery Rev. 2009, 61, 438-456.

30. Dobrovolskaia, M. A.; McNeil, S. E. Understanding the Correlation between in vitro and in vivo Immunotoxicity Tests for Nanomedicines. J. Controlled Release 2013, 172, 456466.

31. Alkilany, A. M.; Lohse, S. E.; Murphy, C. J. The Gold Standard: Gold Nanoparticle Libraries to Understand the Nano-Bio Interface. Acc. Chem. Res. 2013, 46, 650-661.

32. Walkey, C. D.; Olsen, J. B.; Guo, H.; Emili, A.; Chan, W. C. W. Nanoparticle Size and Surface Chemistry Determine Serum Protein Adsorption and Macrophage Uptake. J. Am. Chem. Soc. 2012, 134, 2139-2147.

33. Tenzer, S.; Docter, D.; Rosfa, S.; Wlodarski, A.; Kuharev, J.; Rekik, A.; Knauer, S. K.; Bantz, C.; Nawroth, T.; Bier, C., et al. Nanoparticle Size Is a Critical Physicochemical Determinant of the Human Blood Plasma Corona: A Comprehensive Quantitative Proteomic Analysis. ACS Nano 2011, 5, 7155-7167.

34. Tenzer, S.; Docter, D.; Kuharev, J.; Musyanovych, A.; Fetz, V.; Hecht, R.; Schlenk, F.; Fischer, D.; Kiouptsi, K.; Reinhardt, C., et al. Rapid Formation of Plasma Protein Corona Critically Affects Nanoparticle Pathophysiology. Nat. Nanotechnol. 2013, 8, 772-781.

35. Hill, H. D.; Millstone, J. E.; Banholzer, M. J.; Mirkin, C. A. The Role Radius of Curvature Plays in Thiolated Oligonucleotide Loading on Gold Nanoparticles. ACS Nano 2009, 3, 418424.

36. Nel, A. E.; Mädler, L.; Velegol, D.; Xia, T.; Hoek, E. M.; Somasundaran, P.; Klaessig, F.; Castranova, V.; Thompson, M. Understanding Biophysicochemical Interactions at the NanoBio Interface. Nat. Mater. 2009, 8, 543-557.

37. Bajaj, A.; Samanta, B.; Yan, H.; Jerry, D. J.; Rotello, V. M. Stability, Toxicity and Differential Cellular Uptake of Protein Passivated-Fe3o4 Nanoparticles. J. Mater. Chem. $2009,19,6328-6331$. 
38. Casals, E.; Pfaller, T.; Duschl, A.; Oostingh, G. J.; Puntes, V. Time Evolution of the Nanoparticle Protein Corona. ACS Nano 2010, 4, 3623-3632.

39. Kaufman, E. D.; Belyea, J.; Johnson, M. C.; Nicholson, Z. M.; Ricks, J. L.; Shah, P. K.; Bayless, M.; Pettersson, T.; Feldotö, Z.; Blomberg, E., et al. Probing Protein Adsorption onto Mercaptoundecanoic Acid Stabilized Gold Nanoparticles and Surfaces by Quartz Crystal Microbalance and Z-Potential Measurements. Langmuir 2007, 23, 6053-6062.

40. Chakraborty, S.; Joshi, P.; Shanker, V.; Ansari, Z. A.; Singh, S. P.; Chakrabarti, P. Contrasting Effect of Gold Nanoparticles and Nanorods with Different Surface Modifications on the Structure and Activity of Bovine Serum Albumin. Langmuir 2011, 27, 7722-7731. 41. Oku, N.; Tokudome, Y.; Namba, Y.; Saito, N.; Endo, M.; Hasegawa, Y.; Kawai, M.; Tsukada, H.; Okada, S. Effect of Serum Protein Binding on Real-Time Trafficking of Liposomes with Different Charges Analyzed by Positron Emission Tomography. Biochim. Biophys. Acta, Biomembr. 1996, 1280, 149-154.

42. Mortensen, N. P.; Hurst, G. B.; Wang, W.; Foster, C. M.; Nallathamby, P. D.; Retterer, S. T. Dynamic Development of the Protein Corona on Silica Nanoparticles: Composition and Role in Toxicity. Nanoscale 2013, 5, 6372-6380.

43. Lartigue, L.; Wilhelm, C.; Servais, J.; Factor, C.; Dencausse, A.; Bacri, J. C.; Luciani, N.; Gazeau, F. Nanomagnetic Sensing of Blood Plasma Protein Interactions with Iron Oxide Nanoparticles: Impact on Macrophage Uptake. ACS Nano 2012, 6, 2665-2678.

44. Dobrovolskaia, M. A.; Patri, A. K.; Zheng, J.; Clogston, J. D.; Ayub, N.; Aggarwal, P.; Neun, B. W.; Hall, J. B.; McNeil, S. E. Interaction of Colloidal Gold Nanoparticles with Human Blood: Effects on Particle Size and Analysis of Plasma Protein Binding Profiles. Nanomedicine 2009, 5, 106-117.

45. Deng, Z. J.; Mortimer, G.; Schiller, T.; Musumeci, A.; Martin, D.; Minchin, R. F. Differential Plasma Protein Binding to Metal Oxide Nanoparticles. Nanotechnology 2009, $20,455101$.

46. Doorley, G. W.; Payne, C. K. Cellular Binding of Nanoparticles in the Presence of Serum Proteins. Chem. Commun. (Cambridge, U. K.) 2011, 47, 466-468.

47. Schäffler, M.; Semmler-Behnke, M.; Sarioglu, H.; Takenaka, S.; Wenk, A.; Schleh, C.; Hauck, S. M.; Johnston, B. D.; Kreyling, W. G. Serum Protein Identification and Quantification of the Corona of 5, 15 and 80nm Gold Nanoparticles. Nanotechnology 2013, 24, 265103.

48. Lynch, I.; Dawson, K. A. Protein-Nanoparticle Interactions. Nano Today 2008, 3, 4047.

49. Lundqvist, M.; Stigler, J.; Elia, G.; Lynch, I.; Cedervall, T.; Dawson, K. A. Nanoparticle Size and Surface Properties Determine the Protein Corona with Possible Implications for Biological Impacts. Proc. Natl. Acad. Sci. U. S. A. 2008, 105, 14265-14270.

50. $\quad$ Cedervall, T.; Lynch, I.; Foy, M.; Berggård, T.; Donnelly, S. C.; Cagney, G.; Linse, S.; Dawson, K. A. Detailed Identification of Plasma Proteins Adsorbed on Copolymer Nanoparticles. Angew. Chem., Int. Ed. 2007, 46, 5754-5756.

51. Gessner, A.; Lieske, A.; Paulke, B. R.; Müller, R. H. Functional Groups on Polystyrene Model Nanoparticles: Influence on Protein Adsorption. J. Biomed. Mater. Res., Part A 2003, 65, 319-326.

52. Hauck, T. S.; Ghazani, A. A.; Chan, W. C. W. Assessing the Effect of Surface Chemistry on Gold Nanorod Uptake, Toxicity, and Gene Expression in Mammalian Cells. Small 2008, 4, 153-159. 
53. Hühn, D.; Kantner, K.; Geidel, C.; Brandholt, S.; De Cock, I.; Soenen, S. J. H.; Riveragil, P.; Montenegro, J. M.; Braeckmans, K.; Müllen, K., et al. Polymer-Coated Nanoparticles Interacting with Proteins and Cells: Focusing on the Sign of the Net Charge. ACS Nano 2013, 7, 3253-3263.

54. Janes, K. A.; Albeck, J. G.; Gaudet, S.; Sorger, P. K.; Lauffenburger, D. A.; Yaffe, M. B. Cell Signaling: A Systems Model of Signaling Identifies a Molecular Basis Set for CytokineInduced Apoptosis. Science 2005, 310, 1646-1653.

55. Kou, P. M.; Pallassana, N.; Bowden, R.; Cunningham, B.; Joy, A.; Kohn, J.; Babensee, J. E. Predicting Biomaterial Property-Dendritic Cell Phenotype Relationships from the Multivariate Analysis of Responses to Polymethacrylates. Biomaterials 2012, 33, 16991713.

56. Hellstrand, E.; Lynch, I.; Andersson, A.; Drakenberg, T.; Dahlbäck, B.; Dawson, K. A.; Linse, S.; Cedervall, T. Complete High-Density Lipoproteins in Nanoparticle Corona. FEBS J. 2009, 276, 3372-3381.

57. Zeng, Z.; Patel, J.; Lee, S. H.; McCallum, M.; Tyagi, A.; Yan, M.; Shea, K. J. Synthetic Polymer Nanoparticle-Polysaccharide Interactions: A Systematic Study. J. Am. Chem. Soc. 2012, 134, 2681-2690.

58. Deng, Z. J.; Liang, M.; Monteiro, M.; Toth, I.; Minchin, R. F. Nanoparticle-Induced Unfolding of Fibrinogen Promotes Mac-1 Receptor Activation and Inflammation. Nat. Nanotechnol. 2011, 6, 39-44.

59. Day, A. J.; Prestwich, G. D. Hyaluronan-Binding Proteins: Tying up the Giant. J. Biol. Chem. 2002, 277, 4585-4588.

60. Dreisbach, A.; Van, d. K.; Otto, A.; Gronau, K.; Bonarius, H. P. J.; Westra, H.; Groen, H.; Becher, D.; Hecker, M.; Van Dijl, J. M. Surface Shaving as a Versatile Tool to Profile Global Interactions between Human Serum Proteins and the Staphylococcus Aureus Cell Surface. Proteomics 2011, 11, 2921-2930.

61. Moghimi, S. M.; Hunter, A. C.; Murray, J. C. Long-Circulating and Target-Specific Nanoparticles: Theory to Practice. Pharmacol. Rev. 2001, 53, 283-318.

62. Ehrenberg, M. S.; Friedman, A. E.; Finkelstein, J. N.; Oberdörster, G.; McGrath, J. L. The Influence of Protein Adsorption on Nanoparticle Association with Cultured Endothelial Cells. Biomaterials 2009, 30, 603-610.

63. Crielaard, B. J.; Yousefi, A.; Schillemans, J. P.; Vermehren, C.; Buyens, K.; Braeckmans, K.; Lammers, T.; Storm, G. An in vitro Assay Based on Surface Plasmon Resonance to Predict the in vivo Circulation Kinetics of Liposomes. J. Controlled Release 2011, 156, 307-314.

64. De Paoli Lacerda, S. H.; Park, J. J.; Meuse, C.; Pristinski, D.; Becker, M. L.; Karim, A.; Douglas, J. F. Interaction of Gold Nanoparticles with Common Human Blood Proteins. ACS Nano 2010, 4, 365-379.

65. Åkesson, A.; Cárdenas, M.; Elia, G.; Monopoli, M. P.; Dawson, K. A. The Protein Corona of Dendrimers: Pamam Binds and Activates Complement Proteins in Human Plasma in a Generation Dependent Manner. RSC Advances 2012, 2, 11245-11248.

66. Gentleman, D. J.; Chan, W. C. W. A Systematic Nomenclature for Codifying Engineered Nanostructures. Small 2009, 5, 426-431.

67. Frens, G. Controlled Nucleation for the Regulation of the Particle Size in Monodisperse Gold Suspensions. Nature 1973, 241, 20-22. 
68. Perrault, S. D.; Chan, W. C. W. Synthesis and Surface Modification of Highly Monodispersed, Spherical Gold Nanoparticles of 50-200nm. J. Am. Chem. Soc. 2009, 131, 17042-17043.

69. Gentry, S. T.; Fredericks, S. J.; Krchnavek, R. Controlled Particle Growth of Silver Sols through the Use of Hydroquinone as a Selective Reducing Agent. Langmuir 2009, 25, 26132621.

70. Zhang, H.; Burnum, K. E.; Luna, M. L.; Petritis, B. O.; Kim, J. S.; Qian, W. J.; Moore, R. J.; Heredia-Langner, A.; Webb-Robertson, B.; Thrall, B. D., et al. Quantitative Proteomics Analysis of Adsorbed Plasma Proteins Classifies Nanoparticles with Different Surface Properties and Size. Proteomics 2011, 11, 4569-4577.

71. Zook, J. M.; MacCuspie, R. I.; Locascio, L. E.; Halter, M. D.; Elliott, J. T. Stable Nanoparticle Aggregates/Agglomerates of Different Sizes and the Effect of Their Size on Hemolytic Cytotoxicity. Nanotoxicology 2011, 5, 517-530.

72. Albanese, A.; Chan, W. C. W. Effect of Gold Nanoparticle Aggregation on Cell Uptake and Toxicity. ACS Nano 2011, 5, 5478-5489.

73. Albanese, A.; Tsoi, K. M.; Chan, W. C. W. Simultaneous Quantification of Cells and Nanomaterials by Inductive-Coupled Plasma Techniques. J. Lab. Autom. 2013, 18, 99-104.

74. Eriksson, L.; Trygg, J.; Wold, S. Cv-Anova for Significance Testing of Pls and Opls® Models. J. Chemom. 2008, 22, 594-600.

75. Wold, S.; Sjöström, M.; Eriksson, L. Pls-Regression: A Basic Tool of Chemometrics. Chemom. Intell. Lab. Syst. 2001, 58, 109-130.

76. Liu, R.; Rallo, R.; Weissleder, R.; Tassa, C.; Shaw, S.; Cohen, Y. Nano-Sar Development for Bioactivity of Nanoparticles with Considerations of Decision Boundaries. Small 2013, 9, 1842-1852.

77. Liu, R.; Zhang, H. Y.; Ji, Z. X.; Rallo, R.; Xia, T.; Chang, C. H.; Nel, A.; Cohen, Y. Development of Structure-Activity Relationship for Metal Oxide Nanoparticles. Nanoscale 2013, 5, 5644-5653. 


\section{Figure Captions:}

Fig. 1. Schematic illustrating the protein corona fingerprinting strategy. 1) A library of nanoparticles is mixed with undiluted blood serum, which contains a diverse mixture of proteins. Serum proteins adsorb to the nanoparticle surface, forming a serum protein 'fingerprint'. 2) Proteins are isolated from the surface of the nanoparticles. 3) The identity and quantity of each adsorbed protein is characterized using high-resolution shotgun liquid chromatography tandem mass spectrometry (LC-MS/MS). 4) Nanoparticles are incubated with cells in culture. 5) Net cell association is characterized by elemental analysis. 6) The quantity of each adsorbed serum protein forms a quantitative representation of each nanoparticle formulation within the multidimensional parameter space ' $\mathrm{X}$ '. The net cell association of each formulation defines its location within the response space ' $Y$ '. A function $' \mathrm{Y}=\mathrm{f}(\mathrm{X})$ ' is created that relates the composition of the serum protein corona to cell association. $\mathrm{f}(\mathrm{X})$ can be used to predict the cell association of a distinct nanoparticle formulation from its serum protein corona fingerprint.

Fig. 2. A) Schematic illustrating the combinatorial design of the gold nanoparticle library. 105 formulations were prepared by grafting 3 quasi-spherical gold nanoparticle cores (15, 30 , or $60 \mathrm{~nm}$ ) with one of 67 surface ligands. Surface ligands were classified as 'neutral' (green), 'cationic' (blue), or 'anionic' (red). B) Total adsorbed serum protein density, and C) net A549 cell association for each formulation in the gold nanoparticle library. Cell association was $\log _{2}$-transformed. By geometric considerations, a complete monolayer of albumin (the most abundant protein in serum) on 15,30 , and $60 \mathrm{~nm}$ nanoparticles would give a density of approximately $0.62,0.42$, and $0.32 \mathrm{ug} / \mathrm{cm}^{2}$, respectively, assuming albumin is a uniform sphere of radius $3.5 \mathrm{~nm}$, with a packing density of $78.5 \%$.

Fig. 3. Clustergram showing the serum protein fingerprint formed around each nanoparticle formulation. Rows are identified serum proteins and columns are formulations. See table S5 for full protein names. Formulation names are highlighted based on their classification. Red: anionic gold nanoparticles (GNPs), blue: cationic GNPs, green: neutral GNPs, and orange: silver nanoparticles. Intensity of yellow color is proportional to relative protein abundance. Relative protein abundances are normalized to a standard deviation of 1 across formulations. Cell association is highlighted in magenta. Hierarchical agglomerative clustering with average linkages was performed using Pearson correlation coefficients as a distance metric.

Fig. 4. Model performance. A) Predictivity $\left(\mathrm{Q}^{2} \mathrm{LOO}\right) v s$. accuracy $\left(\mathrm{R}^{2}\right)$ for models created using different parameter sets. Circles show model performance using parameters describing the full serum protein fingerprint ('Fingerprint'), total adsorbed serum protein (BCA), core size by transmission electron microscopy (TEM), local dielectric environment by absorbance spectrophotometry (AS), hydrodynamic diameter by dynamic light scattering (DLS), and zeta potential (ZP). 'Combined' refers to a model that uses BCA, TEM, AS, DLS, and ZP parameter sets together. During model training and validation, gold nanoparticle formulations modified with neutral surface coatings were excluded. B) Measured cell association for each gold nanoparticle formulation $v s$. values predicted from 
the model that uses the full serum protein fingerprint. Red circles indicate anionic formulations, and blue circles indicate cationic formulations. Dashed line shows perfect correspondence between predicted and measured values. Points are mean \pm SEM from three independent replicates. C) Multivariate model performance using a reduced number of serum proteins. The least predictive serum protein was sequentially removed and a new model was trained and validated. Open circles indicate optimal model performance. Closed circles indicate model performance using randomly selected protein sets. Error bars are SD from jackknifing.

Fig. 5. Measured vs. predicted silver nanoparticle (SNP) cell association. Models were trained using the serum protein corona fingerprint from (A) gold nanoparticles (GNPs) only, (B) GNPs \& SNPs, or (B) SNPs only. Cell association values are $\log _{2}$-transformed. Data points are mean \pm SEM from 3 independent replicates.

Fig. 6. Establishing a predictive modeling framework. Nanoparticles possess designdependent physical and chemical properties that determine biological interactions, responses, and outcomes upon exposure to a biological system. Establishing quantitative models that relate biological outcomes to nanoparticle properties enables in silico prediction without explicit experimentation. Datasets from large-scale experiments can be collected in a central database to facilitate the modeling process. The protein corona fingerprinting strategy developed in this study can be expanded from gold and silver nanoparticles to diverse nanoparticle classes. 
Figure 1

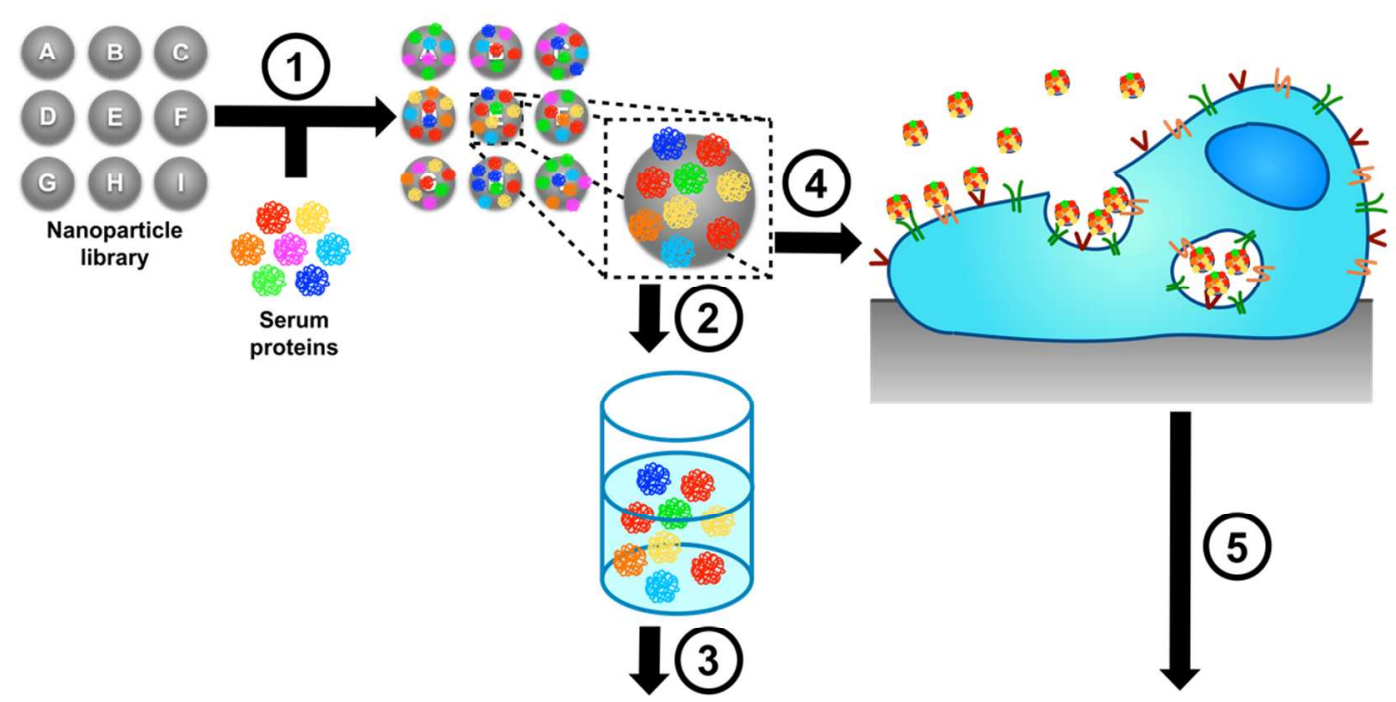

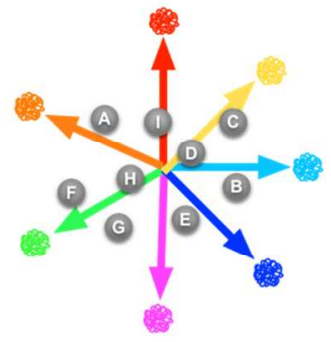

Protein corona parameter space (X)

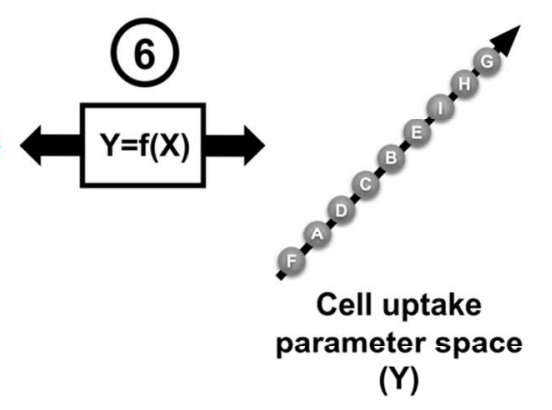

(Y) 
Figure 2

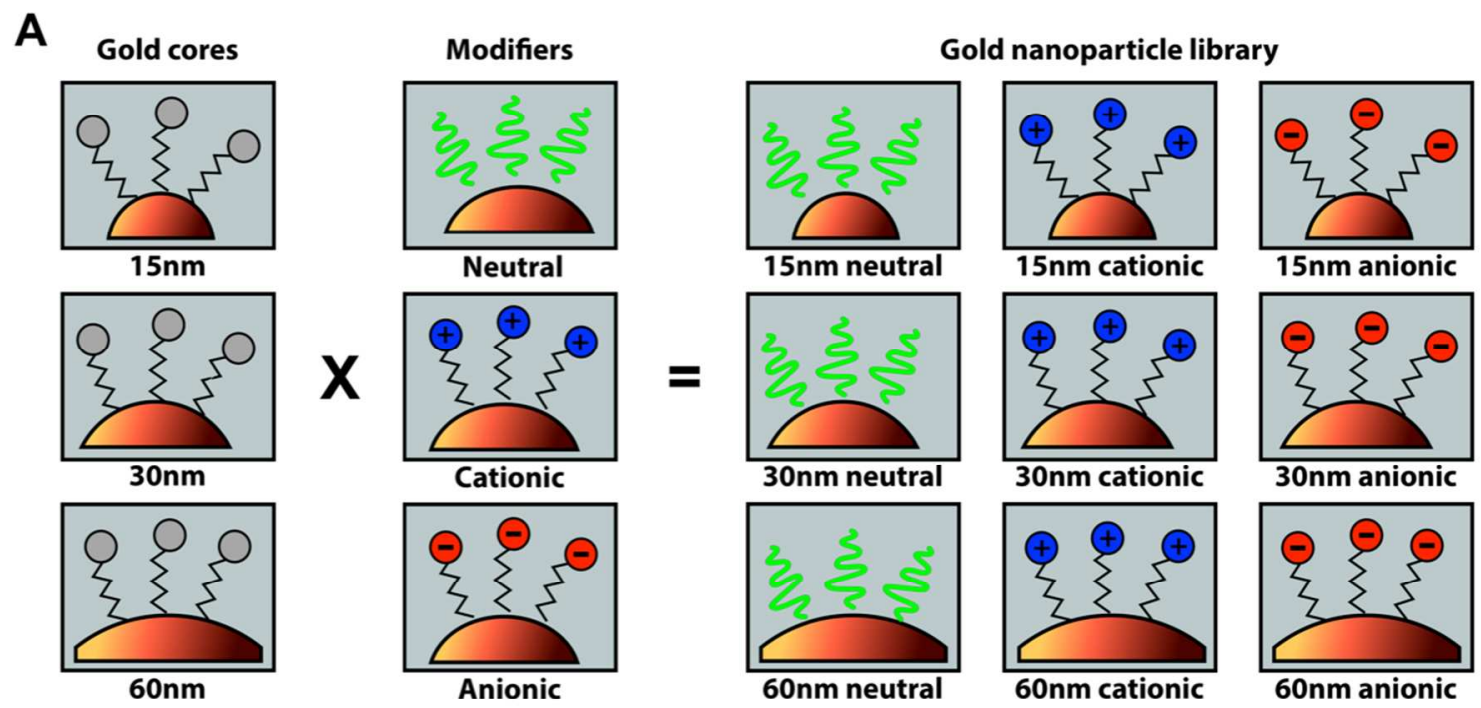

B

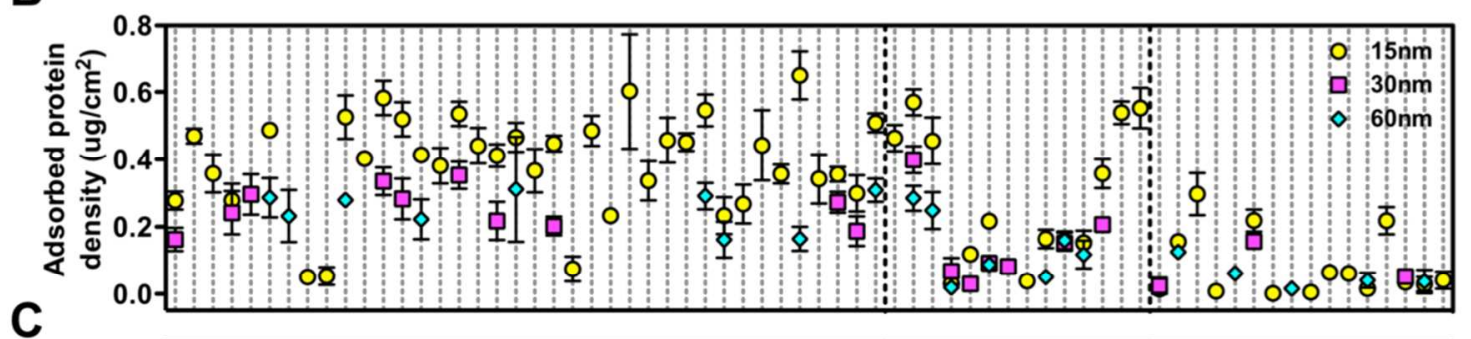

C

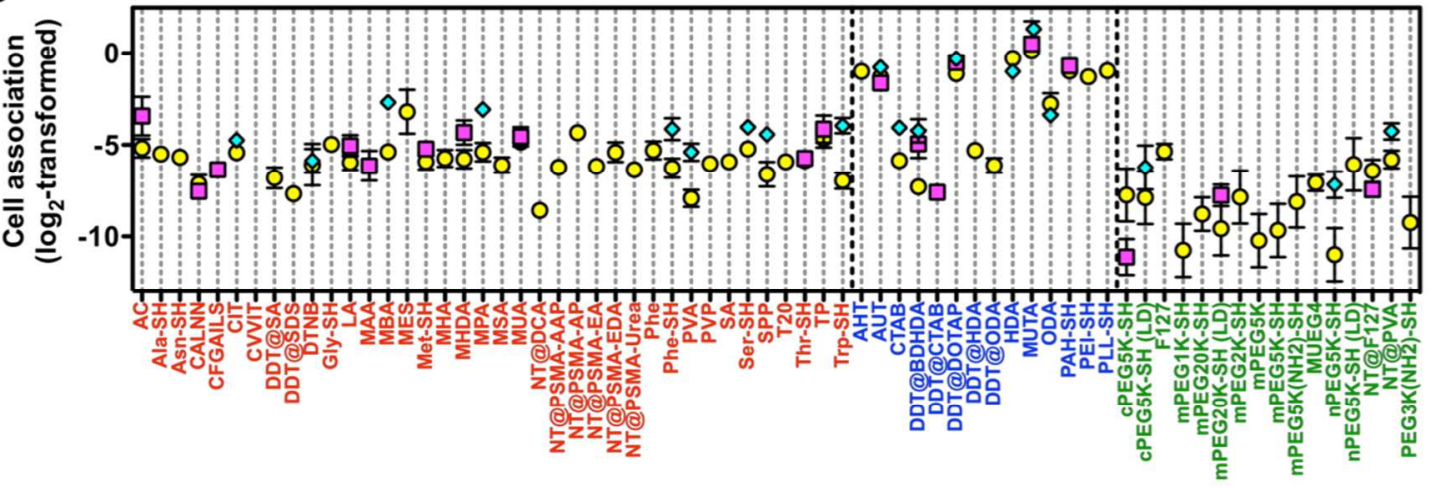


Figure 3
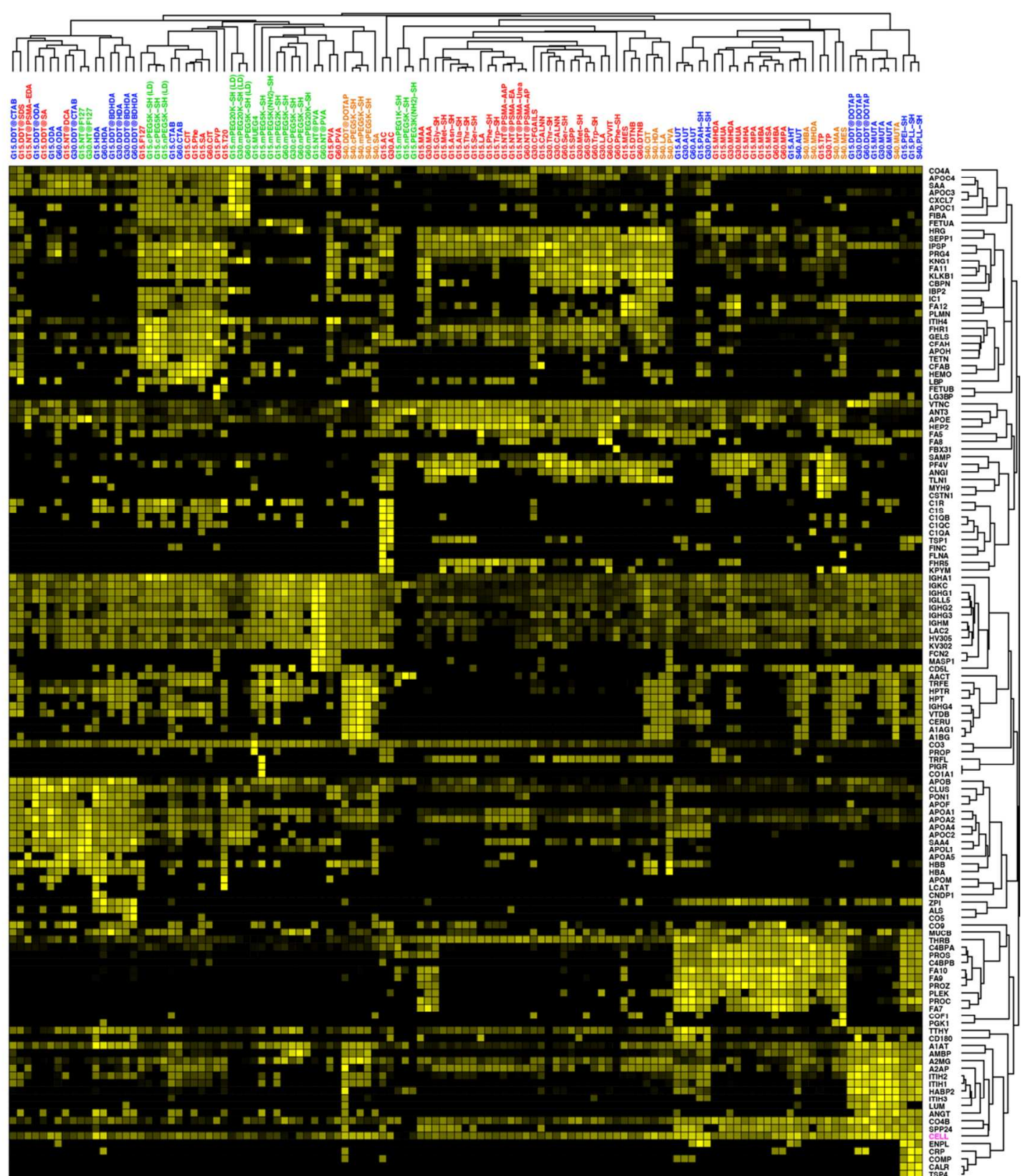
Figure 4

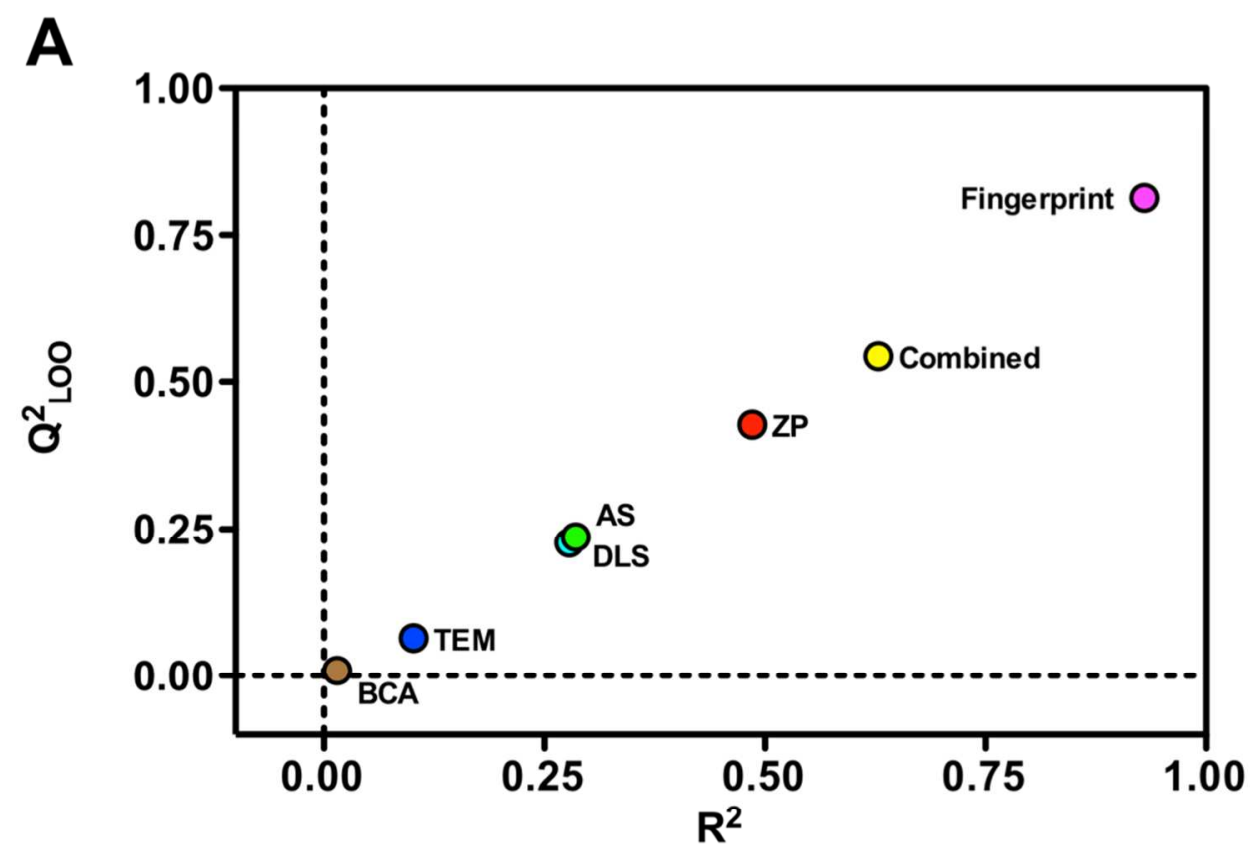

B

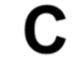

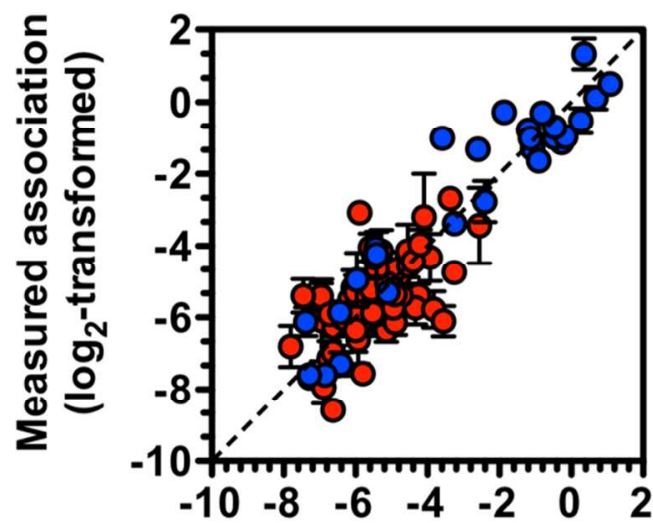

Predicted association ( $\log _{2}$-transformed)

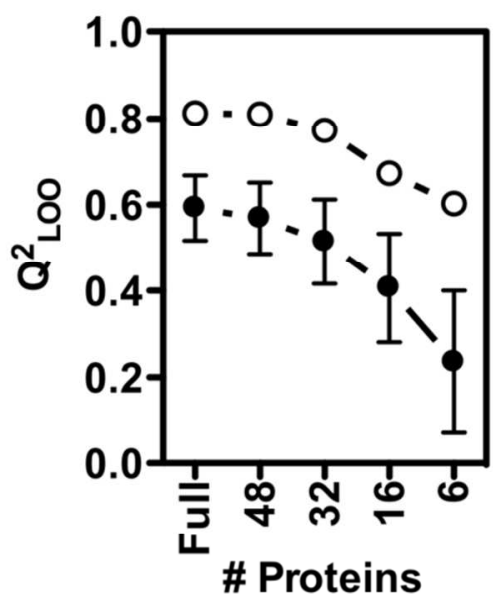


Figure 5
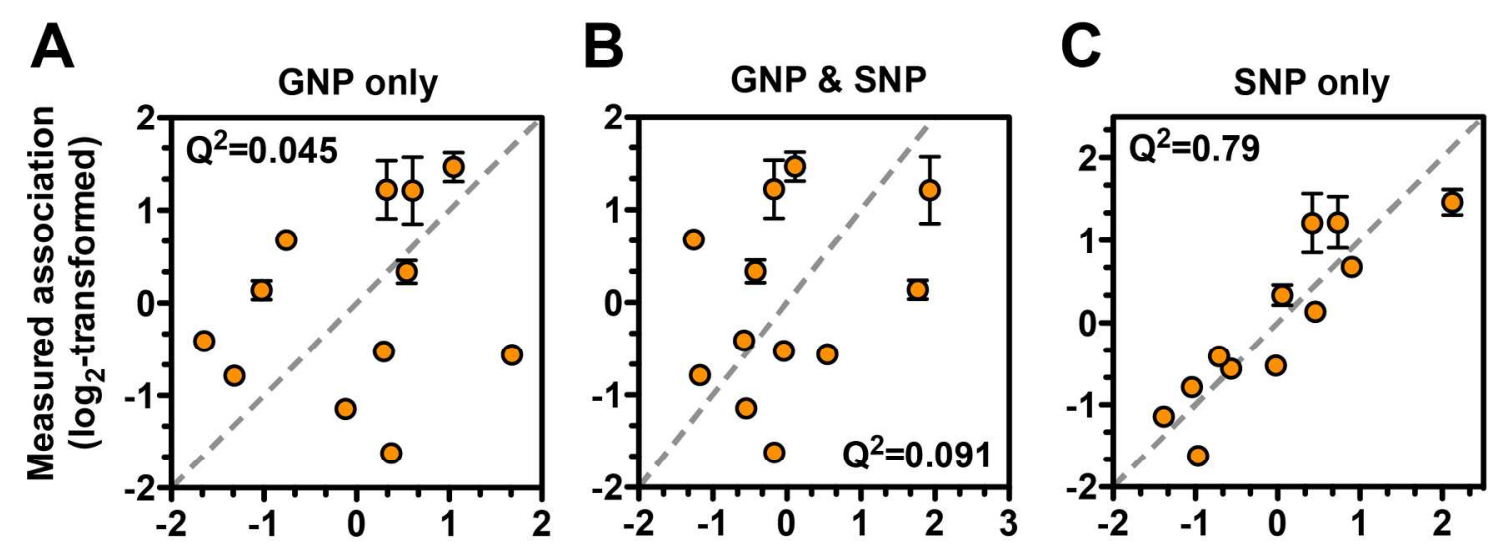

Predicted association ( $\log _{2}$-transformed) 
Figure 6

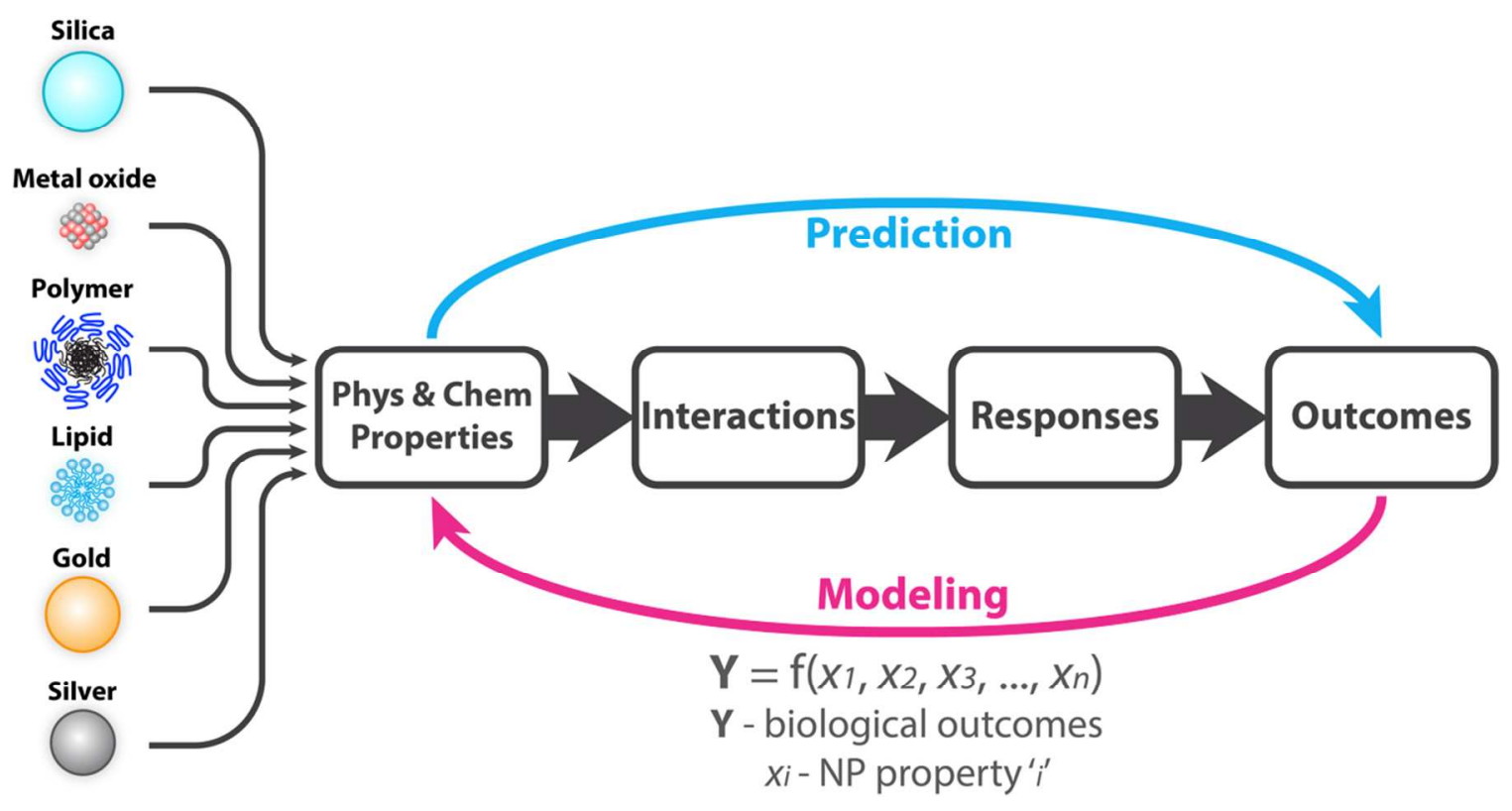


Table 1. Summary of model performance using different parameter sets.

\begin{tabular}{|c|c|c|c|c|c|}
\hline $\begin{array}{l}\text { Parameter } \\
\text { set }\end{array}$ & \# param.i & $\mathbf{R}^{2}$ (\#PCii) & $\mathbf{Q}^{2}$ LOO & $\mathbf{Q}^{2}$ LMO25\% & p-value \\
\hline Fingerprintiii & 64 & $0.93(6)$ & 0.81 & $0.61 \pm 0.18$ & $\sim 0$ \\
\hline TEM $^{\mathrm{iv}}$ & 1 & $0.10(1)$ & 0.065 & $0.15 \pm 0.13$ & 0.0036 \\
\hline HDv & 9 & $0.28(1)$ & 0.23 & $0.19 \pm 0.14$ & $1.2 \times 10^{-7}$ \\
\hline ASvi & 3 & $0.29(3)$ & 0.24 & $0.23 \pm 0.15$ & $3.5 \times 10^{-6}$ \\
\hline ZPvii & 6 & $0.49(2)$ & 0.43 & $0.46 \pm 0.17$ & $1.5 \times 10^{-11}$ \\
\hline BCA viii & 1 & $0.015(1)$ & 0.0088 & $0.053 \pm 0.074$ & 0.26 \\
\hline Combinedix & 26 & $0.63(2)$ & 0.54 & $0.49 \pm 0.18$ & $1.1 \times 10-16$ \\
\hline $\begin{array}{l}\text { Combined + } \\
\text { fingerprint }\end{array}$ & 52 & $0.95(7)$ & 0.86 & $0.63 \pm 0.16$ & $\sim 0$ \\
\hline \multicolumn{6}{|c|}{$\begin{array}{l}\text { i: Number of parameters used in the model after pruning } \\
\text { ii: Optimal number of principal components (PCs) determined during model training } \\
\text { iii: Full serum protein corona fingerprint } \\
\text { iv: Transmission electron microscopy } \\
\text { v: Hydrodynamic diameter from dynamic light scattering } \\
\text { vi: Absorbance spectrophotometry } \\
\text { vii: Zeta potential } \\
\text { viii: Total adsorbed serum protein density from the bicinchoninic acid (BCA) assay } \\
\text { ix: Parameters from TEM, DLS, AS, and ZP combined }\end{array}$} \\
\hline
\end{tabular}

